\title{
Progress of loT Research Technologies and Applications Serving Hajj and Umrah
}

\author{
Mohd Khaled Shambour ${ }^{1} \cdot$ Adnan Gutub $^{2}$ (1)
}

Received: 11 March 2021 / Accepted: 9 June 2021 / Published online: 28 June 2021

(c) King Fahd University of Petroleum \& Minerals 2021

\begin{abstract}
The term IoT technology is associated with many fields, including scientific, commercial, industrial, health, transportation and other fields, which became a necessity of daily life across all segments of society. Artificial intelligence, the Internet of things, data science and big data are among the most prominent fields of technologies in the modern era of e-knowledge, which are increasingly being relied on in many areas of our life. This research is considered very special and urgent affecting around $20 \%$ of the humanities, i.e., Muslim people, whom try to be selected to perform Islamic rituals every year. Given this importance of applying and adapting technologies to serve Hajj and Umrah performers, it is necessary to conduct an analytical study for the technologies and their applications that have been applied in the Hajj and Umrah system. The surveyed studies have been classified, according to their targeted services (focus area), into four main branches, including studies of the two holy mosques and the holy sites, studies of the pre-arrival visitors, housing and services studies, and transportation and crowd management studies. The classified studies were analyzed according to research field, research instrument, statistical method, nature of statistical data, data collection tools, and research citations. The paper outcome opens novel research practical directions selected based on holistic overview of the current technologies analytical survey, which is essential to be considered to improve Hajj and Umrah services coping with today's technology, in addition to discussing other open issues that need further deep research.
\end{abstract}

Keywords Hajj services · Technology applications · Ritual studies $\cdot$ Holy mosques facilities · Makkah research · Islamic pilgrimage

\section{Introduction}

In the past few years, the world witnessed a clear and significant development in the field of IoT technologies in many different sectors and areas of human activities [1]. Nowadays, technology applications have become the essence of the development and prosperity of peoples and countries across the world and in sensitive services [2]. For example, we find medical doctors [3] rely on advanced technical

Adnan Gutub

aagutub@uqu.edu.sa

Mohd Khaled Shambour

myshambour@uqu.edu.sa

1 Custodian of the Two Holy Mosques Institute of the Hajj \& Umrah Research, Umm Al-Qura University, Makkah, Saudi Arabia

2 Computer Engineering Department, Umm Al-Qura University, Makkah, Saudi Arabia equipment to diagnose many diseases that help determine the type of illness with a high degree of accuracy [4]. We also find the effect of applications in the production lines of many industrial and commercial companies that work to reduce time and raise the level of actions [5]. Similarly, technologies play an active and important role in the educational environment, whether in schools or educational centers or universities [6]. The IoT technology is increasingly involved in numerous vertical applications that address a range of individual and community needs [7], including media [8] and data conversations [9], banking services [2], detection systems [10,11], smart cities [12, 13], military applications [14], shopping and movement facilitations [15], local and international education [16], entertainment and medical services [17], and many others [18-22].

IoT Technologies and their applications have also gained tangible attention in the Hajj and Umrah crowd systems [23, 24], which their impact evident in many places in the two holy cities, Makkah and Madinah, including the 
two holy mosques, the holy sites, galleries, libraries, and museums [25]. As considered, Hajj is one of the Five Pillars of Islam, the basic acts that all Muslims are supposed to perform at least once in life. The pilgrimage follows the path of the prophet Muhammad (peace be upon him), as a way of deepening hajjis' connection with the prophet and his teachings. Walking the path of the pilgrimage is also supposed to demonstrate their submission to God ("Allah" in Arabic) [26]. The path of the Hajj follows unique steps, spread out over several days causing some specific massive crowd challenges, as all activities are performed collectively in same time. Hajjis' first arrive at the Miqat (or starting point) for their place of origin. From then on, they enter a holy state called Ihram, i.e., refraining from certain activities, and wearing a plain white cloth. The uniform is meant to show the equality of all the pilgrims [27]. The pilgrims go to Makkah visiting the grand mosque that houses the Kaaba, the holiest site in Islam. At the Kaaba holy mosque, the pilgrims perform tawaf that involves circling counterclockwise around the Kaaba [23]. Then, i.e., after tawaf, the pilgrims go to the nearby hills of Safa and Marwah for walking between them seven times, in ritual called Sa'ay. After Sa'ay, the pilgrims groom their hair. Hajjis then depart Makkah and holy mosque heading to the nearby area called Mina. The pilgrims can stay for a night or two, then on morning of ninth day of Hajj month, they go from Mina to Mount Arafat spending their day until sunset. Pilgrims then leave Mount Arafat to nearby area called Muzdalifah, i.e., heading back to Makkah sleeping in a raw precise area between Mina and Arafat. All the journey involves the normal course of daily prayers and full of gathering and individual activities. Next, Hajjis' go back to Mina with the pebbles to be thrown at stone wall (Jamarat), i.e., known as Ramy Al-Jamarat. Thereafter, pilgrims sacrifice animals that begin the holiday Eid al-Adha, or the feast of the sacrifice, which honors Prophet Ibrahim and Ismail (peace be upon them), followed by activity of pilgrims again cutting their hair. After completing some rituals in Mina and Makkah, many Hajjis will then elect to go on a trip to Madinah, as the other holy city that houses the tomb of Prophet Muhammad (peace be upon him), which is an optional trip that most pilgrimages perform before or after Hajj. This Hajj journey can be visualized in brief as in Fig. 1.

The IoT ecosystem mainly consists of four components, including sensors, communication, data processing, and user interface [28]. The integration of these components allows beneficiaries to connect to their IoT devices and allow them to perform multiple operations, including remote control, data analysis, dashboards, data storage, and security [29]. The overview of the Hajj and Umrah framework forced us to categorize research into four main branches that need a

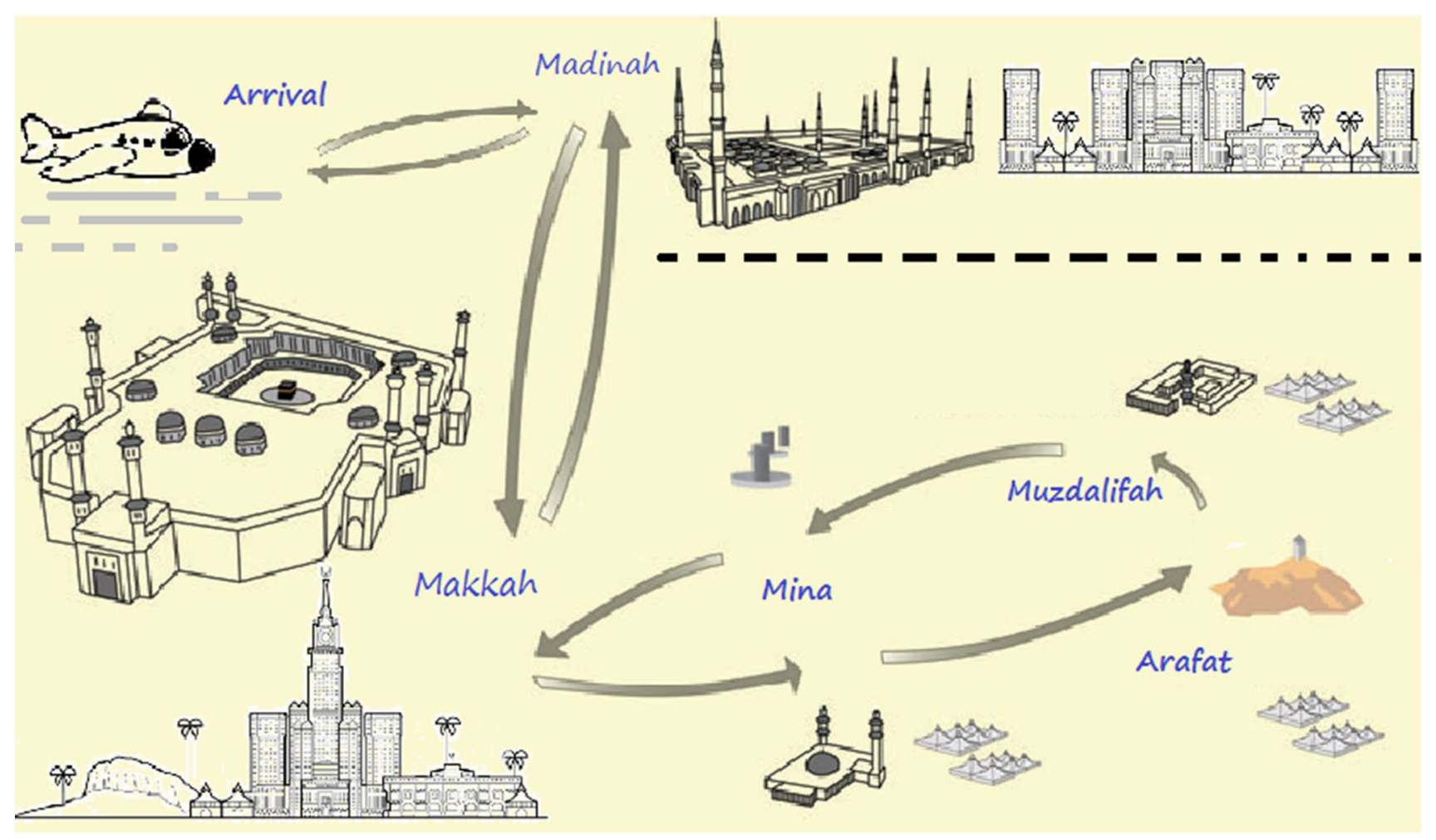

Fig. 1 The Hajj trip overview forming the research four main categorize 
specific professional focus in addition to integration with each other. These four branches have been covering:

1. the two holy mosques and the holy sites (Location-based studies)

2. the pre-arrival studies (Logistics investigation)

3. housing and services studies (Community and social studies)

4. the transportation and crowd management (Human movement/transportation)

These four main research branches must be considered to help clarify the position of research interests of researchers in the field of technologies that serve visitors and service providers., i.e., to the two holy mosques within Saudi Arabia; similar in principle to the sophisticated pedestrianvehicle conflicts within Madinah Holy city [30] and Train service first testing for Hajj in Makkah Holy city [31]. We, in this research, pointed to a set of new technologies and challenges [32], but focused our attention for serving Makkah pilgrims and Umrah performers, as well as Madinah visitors.

The survey analysis background and study further benefitted from the approach of the survey paper of machine learning (ML) algorithms for wireless sensor networks [33], which covered various ML-based algorithms exploring their advantages, drawbacks, and parameters effecting the network lifetime opening the research for more statistical analysis and techniques reasons. However, our study found different variations within the focus of every paper making the overall comparison unfair at this stage. Furthermore, this research is considered one of the limited researches that provides top-view analytical study of the researches that are conducted within the scope of IoT technologies and their applications within Hajj and Umrah systems. Recently published researches are reviewed, analyzed and discussed according to their characteristics. Moreover, several research proposals were recommended, in addition to discussing other open issues that need further deep research. Note also an important objective of this research to become the main trusted reference and starting point as well as motivational fuel for future scientific practical projects for Hajj and Umrah IoT and technology applications researchers, in addition to related local and international decision-makers.

The flow of our research paper is as follows. The second section presents briefing of the previous studies in the field of technologies and their applications within Hajj and Umrah system. The third section briefs the methodology used in this research. The fourth section discussed the analysis and presentation of the results. The fifth section proposes some outcome future proposals ideas that can be applied in the Hajj and Umrah system. The sixth section presented open challenging issues in relation to our review. Finally, the seventh section concludes the paper.

\section{Literature Review}

This section presents the researches that were conducted in the field of the Hajj and Umrah technologies and their applications, which were published in the past five years (2016-2020). The research has been classified into four major branches: The two holy mosques and the holy sites, the pre-arrival studies, housing and services studies, and the transportation and Crowd Management studies.

\subsection{The Two Holy Mosques and the Holy Sites}

The institutions operating in the Hajj and Umrah system develop strategic plans and upgrade and improve the infrastructure to serve millions of pilgrims and Umrah performers and enrich their religious experience, especially in the two holy mosques and the holy sites. According to the Hajj and Umrah vision realization program [34], the branch of the two holy mosques and holy sites received the highest score of contacting points during the guest's trip. The branch contained several parts, including crowd management, services of holy sites, guidance services, and housing in Mina (one of the holy sites in Makkah) [24].

Due to the limited Hajj area space of Mina, many studies represents it as a major challenge of how to efficiently distribute its camps and services. Accordingly, Shambour et al. [35] developed a framework to effectively distribute the Mina camps. The proposed framework depends on the application of artificial intelligence techniques using geographic data for the entire Mina area, considering hard and soft constraints. The recommendations indicated that the proposed technology helps to make use of the maximum capacity of the available resources, which will lead to increase in the capacity of the Mina area. Later, Shambour and Khan [36] proposed a heuristic approach to distribute pilgrims over Mina camps. The proposed algorithm showed an efficient performance, in terms of space allocation, as $80 \%$ of the pilgrims were allocated over $76.2 \%$ of the total accommodation place of Mina area.

Al-Quhtani [37] claimed that MIMO improved the capacity and accuracy of wireless channels, which made it a candidate for the fifth generation $(5 \mathrm{G})$ cellular system. According to that, the author suggested the use of MIMO to improve the performance of large-scale wireless sensor networks in holy sites. This, in turn, leads to many beneficial uses such as public safety and surveillance in all different areas. Haase et al. [38] presented an integer programming model to utilize resource infrastructure to improve the capacity of Mina area and to avoid the densities of dangerous pedestrian in the road network. Simulation results of scheduling pilgrims who performing stoning 
rituals verified the integrity of the scheduling process and the effectiveness of scheduling parameters.

Yasein et al. [39] studied the use of the smart camp in Mina's site using IoT technology. The authors aimed to demonstrate how to intelligently control the various functions and conditions of smart camps using internet-connected sensors. The experimental results showed the success of the implemented case study in capturing sensor data, with the use of a smart mobile phone successfully in remote control, with the possibility of using sensors to obtain services and other information. In another study, Yasein [40] conducted three simulation scenarios for how visitors enter the Prophet's Mosque of Al-Salam Gate during peak times in the holidays. The Author imposed the presence of 10,000 visitors during $16: 40 \mathrm{~min}$ at a rate of 600 visitors per minute and placed a fence surrounding the Al-Salam Gate on three sides.

Felemban et al. [41] simulated the movement of crowds around the Kaaba at the Grand Mosque of Makkah. Allocated cameras in the Grand Mosque were used to collect the required data in order to obtain the parameters necessary to design the model. The Mass-Motion software was used to build the model. The results of the model showed important information about the density and patterns of crowd movement, especially in the important areas of the Makkah Grand Mosque, as related to improve work of [24], which helps to preserve crowd safety and save the effort and cost in the process of organizing crowds [15]. Ali and Al-Masud [42] applied the Bees algorithm to explore the shortest path of health data, collected using wireless body area networks (WBANs), during congestion in the Hajj environment. the proposed algorithm provides efficient results in terms of energy consumption, delay, and transmission time, which is different than the data dissemination and collection work of [18].

In other crowd research, Yasein et al. [43] simulated the large and dynamic movement of crowds in the areas of the Prophet's Mosque in Madinah to reduce risks and support decision-making. This was done by analyzing the simultaneous simulation of the interaction of a group of elements in the model environment, which is an advancement to previous microscopic modeling of large-scale pedestrian-vehicle conflicts in the city of Madinah work [30].

AlQurashi and Altman [44] applied a multilevel and phased model based on individuals to simulate crowd movement on the surface of the Holy Mosque in Makkah, similar to principle-related research [15]. The aim of the enhanced research of [44] was to simulate real behaviors and phenomena with high accuracy rate to improve the complex crowd management process in different circumstances. In addition to automating the decision-making process during mass evacuations in critical incidents, the researchers used a proposed model in a multilevel evidence to manage general crowd and individual behaviors. The results showed that the model was able to support heterogeneity and high density.

An interactive scheduling method for groups of pilgrims has been proposed by Rehman and Felemban [45]. The proposed method reschedules groups of pilgrims according to their preferences to perform the stoning rituals et al.-Jamarat building within Mina area. Safety and time preferences are the primary factors taken into consideration during the optimization process. The method was successfully applied to reschedule the movements of pilgrims during Hajj season 2019 showing interesting results.

The lack of computational requirements in the current sequential systems urged Majid et al. [46] to present a parallel system for large-scale agent-based crowd simulation. The system simulates the circumambulation of pilgrims around the Ka' aba using existing OpenSteer library, where it was simulated for 100,000 pilgrims in 10 frames per second.

Mohamed and Parvez [47] proposed a finite state machine model to simulate the movement of crowds around Ka'aba within Makkah Holy grand mosque. The proposed model aimed to facilitate the touching and kissing of the black stone by pilgrims in a very smart manner. Table 1 shows a summary of previous research related to the two holy mosques and the holy sites. It can be seen (from Table 1) that very little realistic research studies have been performed in the last few years, especially in 2020 that no research has been conducted due to Corona Virus (Covid-19) epidemics.

\subsection{The Pre-arrival Studies}

This section discusses the studies of the performers of Hajj and Umrah, starting from planning the trip in their country until their arrival to the two holy mosques in Makkah and Madinah. Before arrival, there are many tasks and rituals that pilgrims must perform. Therefore, all sectors of Hajj and Umrah work together to facilitate the various services that pilgrims need during their stay to make their rituals convenient and comfortable.

Interestingly, Hamroun and Lajmi [48] adopted a database program to index 1,000 videos related to the rituals needed by Hajj and Umrah performers. The observed results

Table 1 Research collection according to the research branches of two holy mosques and the holy sites

\begin{tabular}{|c|c|c|c|c|c|c|}
\hline \# of Researches (2016) & \# of Researches (2017) & \# of Researches (2018) & \# of Researches (2019) & \# of Researches (2020) & Total & References \\
\hline 1 & 3 & 3 & 6 & - & 13 & [35-47] \\
\hline
\end{tabular}


indicated that the inquiry process is very useful for serving pilgrims as it is able to simulate appropriate rituals for Hajj and Umrah activities.

Shambour et al. [49] used two methods to evaluate websites that provide services related to the rituals of Hajj and Umrah. The researchers used the Google search engine to search for sites that include issues related to visiting the holy cities of Makkah and Madinah. The research results highlighted several general weaknesses in the presence of Islamic websites on the Alexa World site list. Specifically, the two websites "IslamWeb" and "Ministry of Hajj and Umrah" got the highest rating of 4,13 and 4.07 (out of 5), respectively, indicating correct technology direction. There were also weaknesses in providing adequate tools for communication and interaction between all users of Islamic websites. The study also recommended the necessity of professional interest in developing Islamic websites, preserving their contents and updating them periodically.

Elgamal and Alshamarani [50] studied the characteristics of pilgrims in terms of their interests and behaviors during their ritual journey. The researchers obtained data from the records of the Custodian of the two holy mosques Institute for Hajj and Umrah Research (Hajj Research Institute). The collected data were used to explore hidden relationships between the various variables and to present the information visually. In another study, Khoj and Issa [51] proposed a system to clarify the possible ways to distribute the electrical energy and water resources available in Makkah, and the optimal distribution that achieves the minimum efficiency of medical facilities to mitigate risks and conditions, needing more health techno service attention [3]. The consequences of any disaster or pest are considered making huge impact as ensured within the sustainability of their work [51]. Relatively, Utama et al. [52] presented an optimization method to determine the Hajj performers among other candidates for current year quota in Indonesia. The proposed Utama method is interestingly based on Fuzzy logic and human hill climbing ability algorithm. The objective function involved seven different factors, including job, registration date, officer type status, couple status, health, Hajj status, and age [52].

In other works, Khan and Shambour [23] provided an analytical study for the implemented services of Hajj and Umrah mobile applications. The study covered 246 different Apps from Google Play store. Also, a MARS evaluation tool was used to evaluate several Apps of Hajj and Umrah services. Recently, Basalamah \& Rehman [53] presented a survey for Hajj Apps that included 51 Apps, which have been classified according to five main groups, namely, ritual services, location-based services, Context-based Services, navigation services, and other services. The studied apps have been organized according to several factors including individual service, languages, and group of services based on downloads.

Also, Khwaja [54] presented a real-time database management system (DBMS) to improve immigration procedures in Saudi ports during the Hajj season. A free distributed database system, called Sensei DBMS, was implemented and tested on thousands of dummy data records to ensure the system validity. Similarly, in order to promote learning styles that enhance learners' satisfaction, some studies have discussed the possibility of employing the technology of multimedia and virtual reality as an educational source to teach more about Hajj and Umrah rituals and their related issues such as research works presented in 3D-media simulation for hajj [55], virtual Umrah interface satisfaction [56], interactive hajj learning [57], virtual hajj tour [58], augmented reality acceptance while performing hajj [59], virtual simulation hajj teaching [60] augmented reality infographic Umrah technology [61].

Table 2 presents a summary of previous research related to the pre-arrival studies. Similar results were noted as those of previous research conducted in the two holy mosques and holy sites branch. This reveals that the researchers' trend is not very directed toward the topics of the previous two branches, in contrast to the two following branches that will be presented later.

\subsection{Housing and Services Studies}

The services provided in housing, subsistence, shopping and other services are among the basic requirements that are badly needed by the pilgrims and Umrah performers. For instance, Shambour et al. [62] conducted a study that predicts the water and electricity needs within Makkah region in the month of Ramadan for the years 1440-1441 $\mathrm{AH}$ by analyzing data from five previous years. The authors applied NN algorithm to analyze the data and predict the future needed. Relatively, Marjan and Khayat [63] proposed improvement methodology aimed at reducing the distance between service points in the holy sites. Authors employed genetic algorithms (GA) to find the best

Table 2 Research collection according to the research branch of the pre-arrival studies

\begin{tabular}{llllll}
\hline $\begin{array}{l}\text { \# of Researches } \\
(2016)\end{array}$ & $\begin{array}{l}\text { \# of Researches } \\
(2017)\end{array}$ & $\begin{array}{l}\text { \# of Researches } \\
(2018)\end{array}$ & $\begin{array}{l}\text { \# of Researches } \\
(2019)\end{array}$ & $\begin{array}{l}\text { \# of Researches } \\
(2020)\end{array}$ & Total References \\
\hline 2 & 5 & 5 & 2 & 2 & 16 \\
\hline
\end{tabular}


distribution of service points in the holy sites for visitors and pilgrims to obtain the maximum performance. Service points include police cars, ambulances, fire trucks, food, water and other drinks trucks, and surveillance cameras. As a case study, authors applied the algorithm to distribute ambulances at Arafat holy site crowded area.

Khairullah and Ashari [64] have applied an algorithm to search for user preferences regarding Hajj and Umrah companies. The aim was to facilitate the search and obtain the desired results. The study recommended establishing a database for the preferences of pilgrims and Umrah performers, and providing the most important services, such as the location of medical centers that are near Hajj and Umrah companies.

Munir et al. [65] monitored and modeled pollutant emissions in Makkah from the burning of gas, gasoline and diesel consumed in residential homes, road traffic and electricity generation in Makkah at year 2015. Emissions were entered as network sources in the Atmospheric Dispersion Modeling System, and the outputs were presented as ocean maps for different emissions and meteorological scenarios. In other works, Authors in [27,66] studied the benefit of applying visual representation of big data to improve Hajj and Umrah services. Authors presented two cases that were reviewed, the first for the number of pilgrims and workers, and the second for housing pilgrims within Makkah. Researchers [27, 66] emphasized that using data visualization in an exploratory manner is one of the most effective ways to benefit from big data and help improve Hajj and Umrah services. Alkhateeb [67] proposed an iris recognition system to identify missing pilgrims using a neural network probability classifier. The proposed system showed acceptable performance with a recognition rate of $86 \%$. Moreover, Hijry and Olawoyin [68] presented a machine learning method to predict the length of stay of a Hajj patient in the hospital's emergency departments to get the service. The presented method applied NN, linear regression, and logistic regression models.

Baqui and Löhner [69] addressed the real-time monitoring at the Hajj activities. The proposed method is based on taking photos in a sequence of time lapse which are divided into smaller blocks. Afterward, the cross-correlation is applied on each divided block to compute component wise inner product. The histogram of oriented gradients model was used to count the heads in image segments. Finally, the coordinate transformation technique was employed to convert image pixels into 3D world coordinates. Alshammari et al. [70] discussed the feasibility of developing an effective simulation model to track diseases during the Hajj season. The simulation results showed that the spread of the disease is greatly influenced by the demographics of pilgrims and their mobility patterns during the various stages of the Hajj.
A bottom-up segmentation approach of handwritten Arabic texts was introduced by Al-Snoussi and Wahabi [71] to provide lessons and guidelines for Hajj actions according to the spatial and temporal context of the Hajj rituals. The proposed approach extracts the outer isothetic cover of different Arabic text resources in various textual forms including skewed and curved text lines for words and part of words. Batarfi et al. [72] proposed an Arabic semantic lexicon system for Hajj. Authors augmented Arabic dictionary with semantic features and morphological information. The proposed system has two process phases, handling Hajj documents and constructing lexicon processes. The first phase process delivers the hajj file document and convert it to an XML file format. The second phase process receives the produced XML file document and builds a semantic lexicon.

The impact of information and communication technologies on the social experience of Hajj was discussed in the study of Qurashi and Sharpley [73]. The authors argue that despite users' benefits from using smart phone technologies (such as the online Hajj portal, social media sites, Islamic apps, and Wi-Fi services), it negatively impacts their spiritual experience. Elgamal [74] proposed a sentiment analysis method for Hajj-related tweets in English language. The tweets are divided into three stages, including coding, normalization, and part of speech tagging. Then, a Naïve Bayes classifier was applied to classify the type of each Tweet into positive or negative classes. This tweets analysis of [74] is completely different than the security tweets study presented in [75], although the security analysis survey is found very useful within this research for the importance classification strategy to be elaborated later.

In other related researches, Jassas et al. [76] conducted a study on smart system that links medical sensors with cloud computing, i.e., to reduce the time required to serve the largest number of patients during Hajj. The study aimed to design and implement a smart network system for e-health during the Hajj period to solve the problem of delayed arrival of patients' medical information to caregivers. Authors in [77] and [78] presented a fog computing framework to eliminate packet delay and bottleneck problems during Hajj heavy crowded days. The fundamentals points of the presented frameworks focused on handling inquiries of end-users at the fog nodes layer, and effectively managing communications between fog nodes and the cloud server. Also, Nafea in $[79,80]$ proposed a healthcare model based on big data and cloud computing that collects pilgrims' data from Hajj-related ministries in the Kingdom of Saudi Arabia. The collected data are used to extract patterns that control disease spread during Hajj. In the same context, Eldein et al. [81] studied the healthcare procedures in Hajj and Umrah system. Authors in [81] discussed the detailed requirements for the proposed system to develop a mobile healthcare system. Related issues have been also discussed 
in [82-86]. Moreover, a survey of technological issues in the health monitoring of pilgrims has been conducted in [87] and its links to security have been covered in $[4,5]$.

For real-time language assistance services during Hajj and Umrah visits, Abdelazeez and Shaout [88] provided a multilingual translation system for pilgrims to assist them while performing their rituals. Many studies have employed variety of smart apps to support and serve Hajj and Umrah performers on their holy journey, such as tracking, monitoring, learning, locating, recognition, notifications, and many other services as discussed differently in researches, such as Hajj app for iOS [89], dynamic crowd monitoring [90], Android Hajj monitoring application [91], HAJJRAH application [92], smart face recognition for lost \& found [26], intelligent items identifying [93], Hujjaj tracking [94], tracking losses within crowds [95], intelligent HAJJ guide [96], tracking within crowds [97], integrating social media with mobile apps for Hajj management [98], M-HAJJ DSS [99], and context-aware mobile framework for Hajj management [100].

Table 3 provides a summary of previous research related to the housing and services studies. Although the total number of researches reached 43, with an average of 8.6 researches annually, we find that the number of researches continues to decline over the years.

\subsection{Transportation and Crowd Management Studies}

Yasein and Alharthi [101] studied several technological techniques used in tracking and guiding pilgrims during the Hajj and Umrah seasons. The researchers compared different systems-GPS, land-based tracking systems, RFID/ NFC, Bluetooth, Wi-Fi, Scene analysis based on image examination systems, Barcode systems and Hybrid Solutions. The researchers pointed out the possibility of making use of these systems and employing them to serve pilgrims and Umrah performers. Osman [102] proposed a system to ensure safety and guidance for pilgrims while performing Hajj and Umrah rituals. The NFC technology was applied to track and identify pilgrims in crowded places.

Alkhuzaim and Altahhan [103] conducted a study to estimate crowd density at the Grand Mosque using neural network $(\mathrm{NN})$ algorithm. The study aimed to provide guidance to pilgrims and visitors to increase awareness and safety. The authors recommend the NN model because it has an effective image classification performance, which can be used in estimating crowd density and classifying images and videos in a crowded scene. Relatively, Jabbari et al. [104] proposed a framework for solving crowd collision problem by using a mobile device to sense the risk of collision before it occurs. The researchers based their work on using wristbands of personal information and locater chip. Bracelets have been used assuming "low-power Bluetooth" to locate persons by sending signals to the sensors on the roads that the pilgrims walking to discover the crowds. These crowd analysis remarks are based on Hajj simulations research of huge gatherings [15] as well as right of way interactions [24].

Data dissemination and collections [18] as well as head detection methods of Musa et al. [105] are useful to count the pilgrimage crowds by segmenting the head regions from static images. The researches aimed to determine the potential of stampede early in order to alert people to take necessary procedures. Similarly, Khan et al. [106] proposed a framework for improving crowd management within Hajj activities assuming computer vision technology to be used to analyze video footage automatically. Authors applied different contrast video footage, previously recorded manually, to be able to measure and evaluate the crowds. Then, models were built using neural networks to extract important information such as estimating crowd real-time density, determining the prevailing patterns of movement, and discovering and identifying areas of congestion [24].

An optimization method was suggested by Felemban et al. [107] to schedule the movement of pilgrims using the train during the Hajj days, as previously tested in research $[25,31]$. The authors of [107] identified three factors that affect the scheduling process, which are the type of train movement, the location of the pilgrim camp, and the camps to the permitted stations and vice versa. The proposed method was applied during Hajj season 2019, and an analytical comparison was made between the actual and scheduled times for each train station.

Seddiq et al. [108] studied the evaluation of crowd congestion using variable resolution clustering. The study aimed at creating an algorithm capable of detecting crowding environments and assessing the level of gathering severity in three levels of the scale as follows: No congestion, mild congestion, and severe congestion, different than old work of [30]. The Seddiq study [108] recommended a demonstration of the usefulness of multi-circular clustering in assessing massive crowd congestion. Interestingly, Amer and AlMatrafi [109] used multi-agent system (MAS) to organize

Table 3 Research collection according to the research branch of housing and services studies

\begin{tabular}{lllllll}
\hline $\begin{array}{l}\text { \# of Researches } \\
(2016)\end{array}$ & $\begin{array}{l}\text { \# of Researches } \\
(2017)\end{array}$ & $\begin{array}{l}\text { \# of Researches } \\
(2018)\end{array}$ & $\begin{array}{l}\text { \# of Researches } \\
(2019)\end{array}$ & $\begin{array}{l}\text { \# of Researches } \\
(2020)\end{array}$ & Total References \\
\hline 10 & 10 & 9 & 8 & 6 & 43 & {$[4,5,26,27,62-100]$} \\
\hline
\end{tabular}


negotiations between Hajj administrations and campaign organizers, i.e., to evacuate the pilgrims during peak times. The MAS proposed system set timetable schedules for pilgrims traveling from Arafat to Muzdalifah in addition to automated RFID gates, which can detect buses that do not adhere to the plan. The study indicated the need to use a multi-agent system to automate negotiations between Hajj authorities and travel agents to make the schedule setting process open and fair, in addition to using automated RFID gates to prevent buses without a valid card to reach the holy Makkah city.

Namoun et al. [110] applied the support vector machine with the concept of fuzzy logic to simulate the behaviors and movements of pilgrims in panic situations. The authors aimed to find appropriate evacuation models to avoid the possibility of disaster occurring. The results showed that the algorithm can select the best representative crowds of pilgrims that better reflect their behavior. Differently, to understand the behavior of the pilgrims crowd during Hajj days, Felemban et al. [111] employed an application system to collect and analyze pilgrims data in a space and time domains to explore their movement information such as selected path, starting time, duration time, and the movement speed.

A machine learning approach for detecting the crowd congestion in Hajj was proposed by Islam et al. [112]. The proposed system employed three bracelet sensors to collect the required data, including the sensors of temperature, humidity, and accelerometer. The collected data were then used to predict stampede potential using K-Nearest Neighbors and decision tree algorithms. Similarly, a framework for distributing and controlling visitors of a crowded area was proposed by Mohamed et al. [113]. This proposed framework consists of three layers, including sensor, management, and interface layers. These layers are used for collecting data, analyzing data, and providing appropriate decision, respectively. The proposed framework aimed to provide users with information about the current condition of roads and doors, the locations of non-congested areas, and the locations of friends and groups.

A framework for managing and monitoring Hajj crowed was offered by Nasser et al. [114]. Authors discussed the use of smart monitoring of paths in the Mina's tents and AlJamarat building as a congestion detection and prediction tool. The proposed framework was evaluated against three scheduling mechanisms, first-in-first-out, priority queuing, and weighted round robin mechanisms, where interesting remarks have been gained.
Mahmood et al. [115] presented an agent-based crowd simulation framework for crowd evacuation strategies. The proposed framework is designed to simulate the behavior of large crowd in a real scale spatially environment and to assess evacuation strategies. In the same context, a game theory approach for crowd management service during Hajj was introduced by Nasser et al. [116]. The main objective of the study was to avoid bottleneck for pedestrians during stoning ritual at the Jamarat building. Furthermore, Mnasri and Farhat [117] studied the crowd dynamics of pilgrims in the Jamarat building during the Hajj and presented three proposals to improve crowd movement management. Alazbah and Zafar [118] employed a convolutional neural network algorithm to detect congestion in the Jamarat building during ritual stone-throwing. The algorithm was trained using different classification images taken from actual video of crowds walking on the Jamarat route. The proposed algorithm presented the crowded condition according to three categories including crowded, semi-congested, and normal. Authors in $[119,120]$ studied bus traffic during the 2018 Hajj season using a large-scale Global Positioning System (GPS). Data of about 20,000 buses were collected, analyzed and visualized through an advanced interactive platform. Also, the algorithm presented in [120] applies the concept of avoiding spatial anomaly by ensuring that there is no crossmovement of the evacuees during the evacuation.

Alrabghi [121] offered a flow simulation model for passengers at Hajj terminal in the king Abdulaziz international airport during peak times. Various simulation scenarios were applied to explore the best waiting times for passengers. Results show that the passengers' flow could be improved by enhancing the procedures of certain policies without the need to increase the existing resources. Authors in [122, 123] discussed the efficiency of using wireless and mobile technologies in large crowded events. The author discussed the use of radio frequency identification (RFID) to monitor and control crowd movements, as well as the use of a fog computing system that reduces processing and communication costs on the cloud system. Also, Jabbari et al. [124] proposed an intelligent crowd system to avoid the potential for disaster during Hajj by using real-time data analyzes of Bluetooth Low Energy data. The proposed system can define multiple crowd measures including direction, location, velocity, and density. Other related works have been also discussed in [125-130].

Table 4 shows a summary of previous research related to the transportation and crowd management studies. The results

Table 4 Research collection according to research branch of transportation and crowd management studies

\begin{tabular}{|c|c|c|c|c|c|c|}
\hline \# of Researches (2016) & \# of Researches (2017) & \# of Researches (2018) & \# of Researches (2019) & \# of Researches (2020) & Total & References \\
\hline 3 & 6 & 4 & 15 & 2 & 30 & [101-130] \\
\hline
\end{tabular}


indicated that the total number of researches reached 30 , and that half of these researches were conducted in 2019, and it was noticed that the lowest number of researches in all branches studied was in 2020 . We strongly expected that the main reason behind this is because of the spread of the Covid-19 pandemic. In addition to the precautionary measures that make it difficult for researchers to conduct their studies during that time.

Considering all these related works, we attempt to overview Hajj and Umrah research as overall complementary study that has been remarked as fundamental background within this scientific review work. This holistic overview made-up our methodology of four stages classification as elaborated next.

\section{Methodology}

The research methodology used in this paper is illustrated in Fig. 2 as four stages for understandable consideration. The first stage begins with an overview of the previous research works related to the technologies and their applications in Hajj and Umrah system. We are categorizing the first stage into their related research fields, including studies of the two holy mosques and the holy sites, the pre-arrival studies, housing and services studies, and the transportation and crowd management studies.

In the following stage, Stage 2, the categorized studies were further classified according to six sub-categories: research field, research instrument, statistical method, nature of statistical data, data collection tools, and research citations. Then, Stage 3 covers analysis of the results as thoroughly presented and discussed in a separate stage. Finally, Stage 4 comes from the user prospective looking into applications and modern technologies that can be applied in the Hajj and Umrah system, which are suggested and discussed in depth, in addition to discussing other open issues that need further deep research.

\section{Data Analyses and Discussion}

This section presents the results of research analysis according to the six subcategories mentioned earlier. Table 5 shows that previous research falls into nine scientific research fields: artificial intelligence (AI) and machine learning,

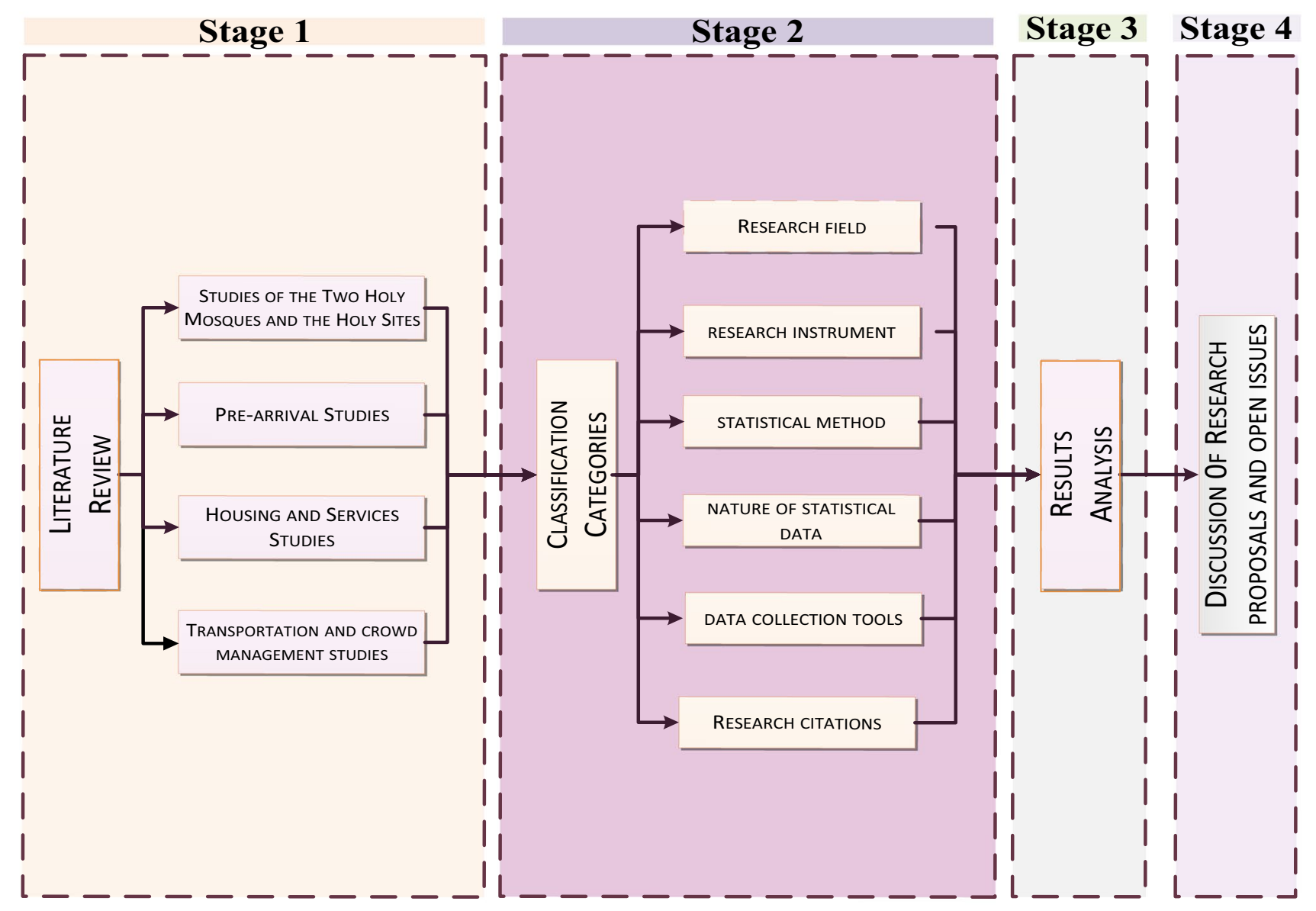

Fig. 2 Research methodology 
Table 5 Research classifications according to scientific fields

\begin{tabular}{|c|c|c|c|c|c|c|}
\hline Scientific fields & $\begin{array}{l}\text { \# of } \\
\text { Researches } \\
(2016)\end{array}$ & $\begin{array}{l}\text { \# of } \\
\text { Researches } \\
(2017)\end{array}$ & $\begin{array}{l}\text { \# of } \\
\text { Researches } \\
(2018)\end{array}$ & $\begin{array}{l}\text { \# of } \\
\text { Researches } \\
(2019)\end{array}$ & $\begin{array}{l}\text { \# of } \\
\text { Researches } \\
(2020)\end{array}$ & References \\
\hline $\begin{array}{l}\text { Artificial intelligence }(\mathrm{AI}) \text { and } \\
\text { machine learning }\end{array}$ & 7 & 3 & 8 & 16 & 5 & $\begin{array}{l}{[26,35,36,38,42,45,46,51,52,} \\
\quad 62-64,67-69,74,89-98,100,102, \\
103,105,107,109-112,118-120 \\
124\end{array}$ \\
\hline Simulation and modeling & 3 & 3 & 3 & 6 & - & $\begin{array}{l}{[38,40,41,43,44,46,47,65,70,110,} \\
\quad 114-117,121]\end{array}$ \\
\hline Image processing & - & 4 & 2 & 4 & - & $\begin{array}{l}{[26,67,69,71,93,103,105,106,108,} \\
\quad 118]\end{array}$ \\
\hline Data science and data big & 1 & 2 & 1 & 3 & - & {$[27,49,50,66,71,119,120]$} \\
\hline Internet of things (Iot) & 1 & 5 & 1 & 7 & 1 & $\begin{array}{l}{[39,76-82,91,104,108,112,113,} \\
122,123]\end{array}$ \\
\hline Data communication & 2 & 2 & 7 & 4 & - & $\begin{array}{l}{[37,83,85-87,90,101,122-124,} \\
\quad 126-130]\end{array}$ \\
\hline Database & 2 & 2 & - & - & - & {$[48,55,69,88]$} \\
\hline Virtual and augmented reality & 1 & 2 & 4 & - & - & {$[55-61]$} \\
\hline Information system & 1 & 2 & 1 & 1 & 2 & {$[23,53,71-73,88,125]$} \\
\hline Total percentage of scientific fields & $15.1 \%$ & $21.0 \%$ & $22.7 \%$ & $34.5 \%$ & $6.7 \%$ & \\
\hline
\end{tabular}

simulation and modeling, image processing, data science and big data, the Internet of things (IoT), database, virtual augmented reality and information system.

This work has been investigated all together as studies published per year via percentage of researches published in 2019 as being the largest resulting at $34.5 \%$. The works have been reconsidered as percentages of fields compared to each other, as shown in Fig. 3.

The results (Fig. 3) showed that the bulk of the reviewed research works focused on the field of artificial intelligence and machine learning with ratio $32.2 \%$ followed by modeling and simulation, data communication, and IoT, all with similar ratio of $12.7 \%$. Then comes image processing field with $8.5 \%$. It should be noted that missing research in other important areas in the Hajj and Umrah system, can be noted as the field of security and privacy which is becoming very essential in the coming years.

Table 6 presents research instruments adopted by researchers in their research works, which were limited to seven tools: real implementation, simulation and modeling, framework, visualization, survey study, data mining, and evaluation criteria. Results showed that the research works published in 2019 were the largest with $30.8 \%$ of the total published work, whereas 2020 was the lowest with $6.7 \%$.

The results in Table 6 have been summarized as percentages shown in Fig. 4, in order to grasp the related research situation. The review showed that real implementation was the most used tool among researchers as ratioed at $42.3 \%$,
Fig. 3 Trends of scientific field studies

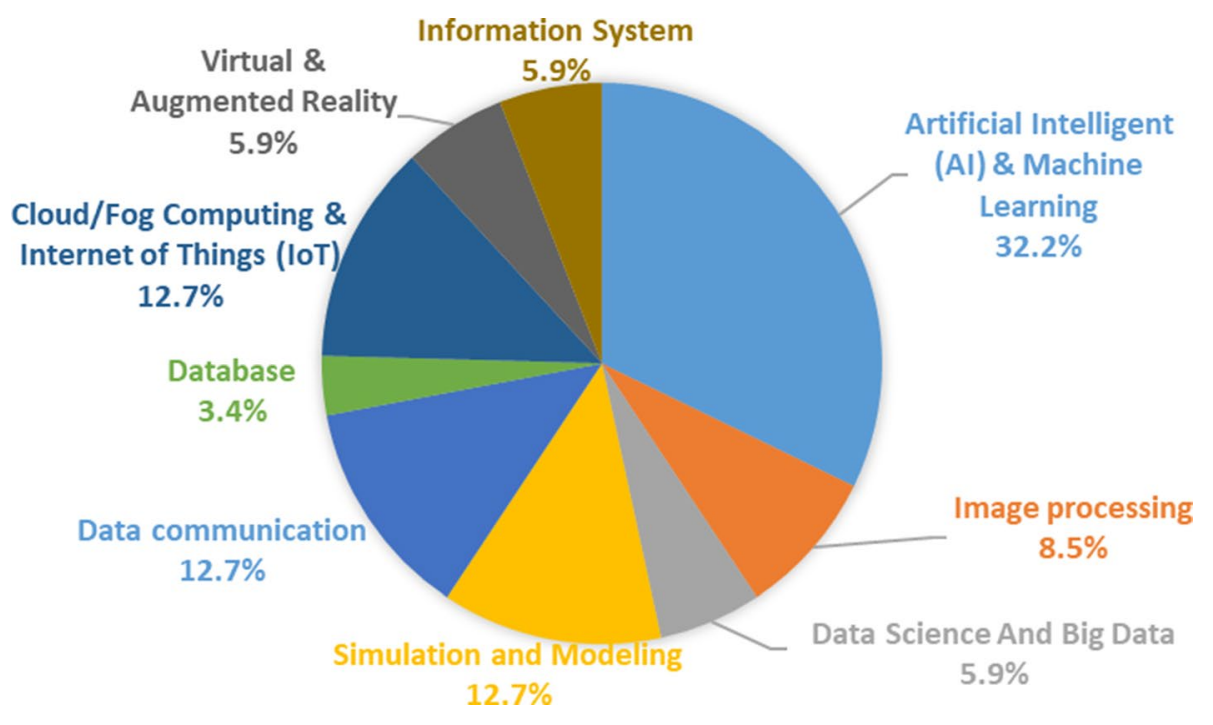


Table 6 Research classifications according to research instruments

\begin{tabular}{|c|c|c|c|c|c|c|}
\hline Research instruments & $\begin{array}{l}\text { \# of } \\
\text { Researches } \\
(2016)\end{array}$ & $\begin{array}{l}\text { \# of } \\
\text { Researches } \\
(2017)\end{array}$ & $\begin{array}{l}\text { \# of } \\
\text { Researches } \\
(2018)\end{array}$ & $\begin{array}{l}\text { \# of } \\
\text { Researches } \\
(2019)\end{array}$ & $\begin{array}{l}\text { \# of } \\
\text { Researches } \\
(2020)\end{array}$ & References \\
\hline Real implementation & 7 & 8 & 7 & 18 & 4 & $\begin{array}{c}{[26,36,39,42,45,46,48,52,54,62-64,67-69,} \\
71,72,74,76,88-96,99,100,102,105-108, \\
111,112,118-120,124,127,129,130]\end{array}$ \\
\hline Simulation and modeling & 3 & 4 & 4 & 7 & - & $\begin{array}{l}{[37,38,40,41,43,46,47,51,58,70,109,110,} \\
\quad 113-117,121]\end{array}$ \\
\hline Framework & 4 & 7 & 5 & 4 & 1 & $\begin{array}{l}{[35,37,44,51,77-83,85,86,97,98,104,113} \\
\quad 122,123,126,128]\end{array}$ \\
\hline Visualization & 2 & 1 & - & 2 & - & {$[27,65,66,119,120]$} \\
\hline Survey study & 2 & 4 & 5 & - & 2 & {$[23,53,55-57,59-61,73,78,87,92,101,125]$} \\
\hline Data mining & - & 1 & - & 1 & - & {$[50,71]$} \\
\hline Evaluation criteria & - & - & 1 & - & - & [49] \\
\hline $\begin{array}{l}\text { Total percentage of } \\
\text { research instruments }\end{array}$ & $17.3 \%$ & $24.0 \%$ & $21.2 \%$ & $30.8 \%$ & $6.7 \%$ & \\
\hline
\end{tabular}

Fig. 4 Percentages of research instruments compared as overall studies

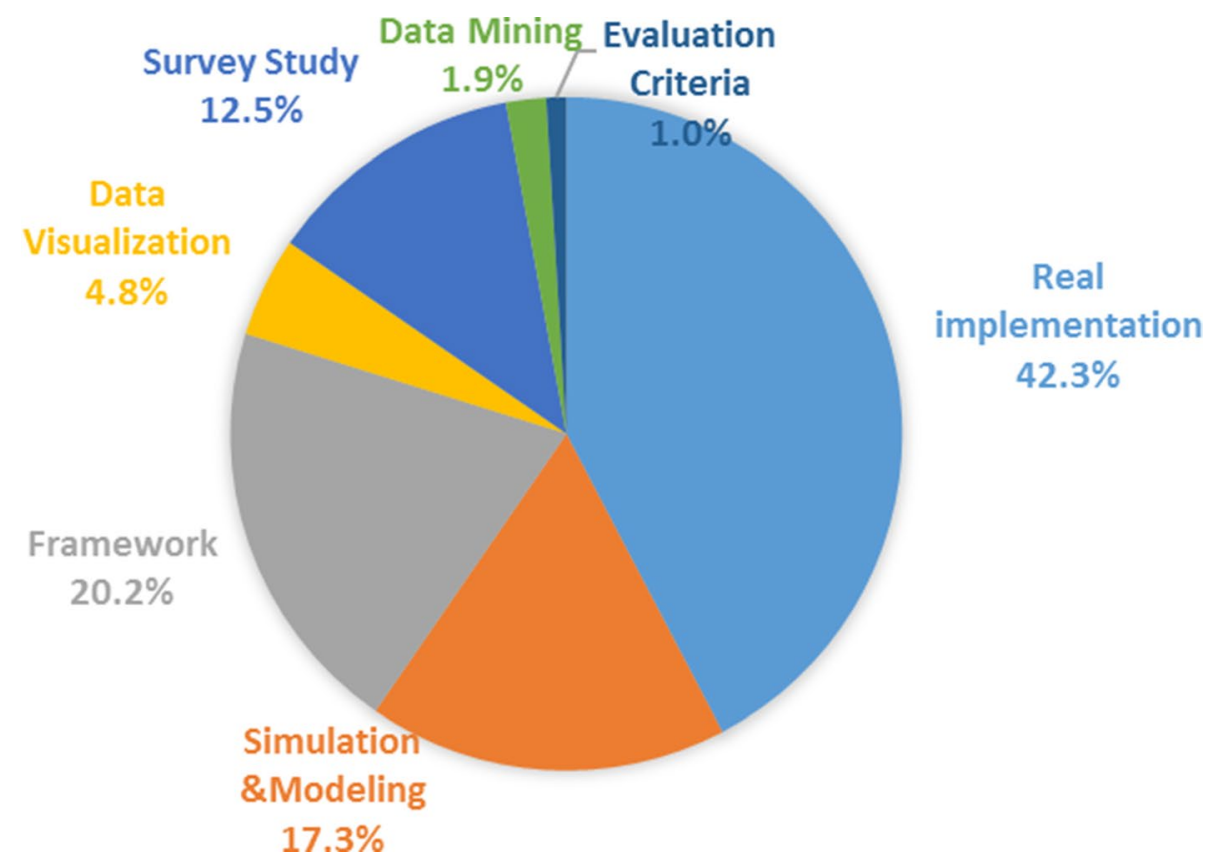

followed by framework analysis at $20.2 \%$, then modeling and simulation at $17.3 \%$. The survey study has been found less attractive by ratio of $12.5 \%$ as understandable ration due to its trusted difficulty in collecting among Hajj and Umrah visitors. The least used tools were data mining by $1.9 \%$ and evaluation criteria with $1 \%$ as following the evolving method of data visualization showing $4.8 \%$.

Table 7 also displays the classification of the research works according to the used statistical methods, which was classified either as descriptive or Inferential or not available (N/A). Results showed that the research works published in 2019 was the largest with $31.6 \%$ of the total published work, whereas 2020 was the lowest with $7.1 \%$.
The results, as shown in Fig. 5, showed that the largest part of the research was based on descriptive statistics by 73.5\%. Moreover, the research based on inferential statistics did not exceed $2 \%$ of the total research, whereas the rest used N/A as not applicable standard statistical schemes based on the unique Hajj and Umrah ritual situations.

Table 8 shows the classification of the research works according to the nature of the statistical data, i.e., study data type, which consists of quantitative and qualitative or neither both approaches. These types cannot be standardized since they do not link to normal situations as found naturally in life. Similar to the previous results, the research works published in 2019 was the largest, while the year 2020 was the 


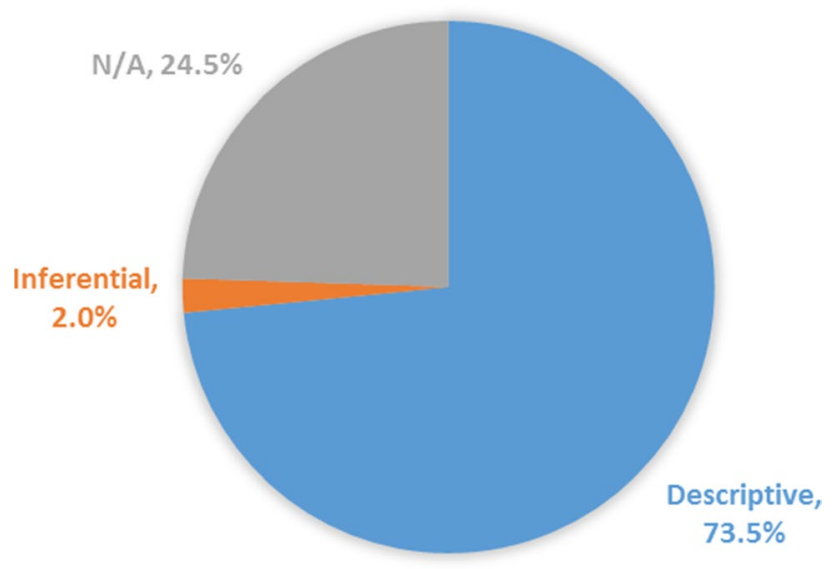

Fig. 5 Percentages of research statistical method used

lowest with $30.4 \%$ and $6.9 \%$ of the total published works, respectively. The Hajj and Umrah activities are showing interesting features being investigated from different point of views as summarized in Fig. 6.

The results of Table 8 (visualized in Fig. 6) indicated that majority of $68.6 \%$ of the researches relied on analysis of quantitative data, either continuous or discontinues. Other $8.8 \%$ of the researches based their work on qualitative descriptive data covering ordinal or nominal schemes. Our review turned out that the percentage of researchers who have relied on mixing type data analysis, noted as N/A in Table 7, was the around 22.5\%. These N/A not standard statistical data type found using other technical non-standard interesting approaches worth adopting.

The data collection scheme can be different among researches working on Hajj and Umrah activities. For example, Table 9 lists the works classified by mostly using virtual data, basing on software/ technical equipment/ camera tools, involving questionnaire, using official reports and observations, adopting interviews and other technical non-standard interesting approaches (noted as N/A). The results showed

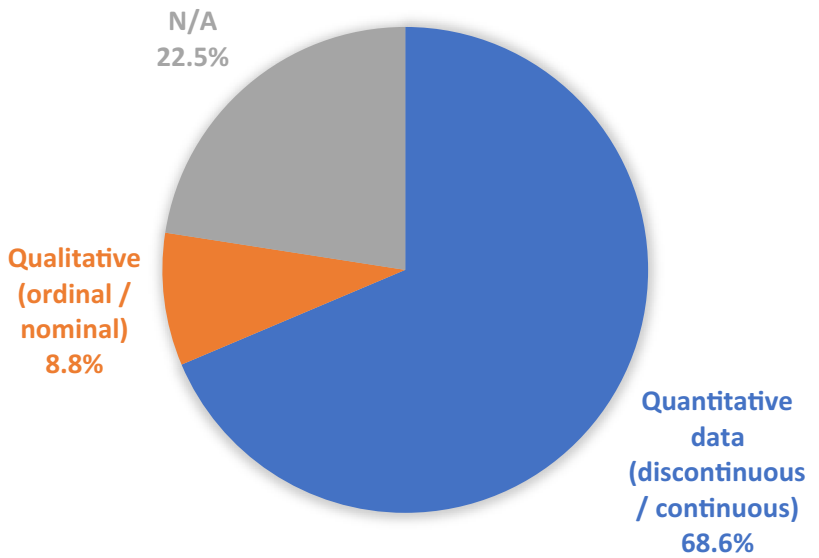

Fig. 6 Percentages of research statistical data type adopted

that the largest part of research work was conducted in 2019 at $31.7 \%$ of the total published works, and the lowest part was found in 2020 at $6.9 \%$.

The data collection tactics are summarized as shown in Fig. 7. In general, the most used approach is the official reports and observations showing $24.8 \%$ as they are very clear and fixed. However, their remarks can be considered limited since they do not go deep into the problems or critical situations except what has been reported. Therefore, $18.8 \%$ of researches used virtual data modeling as well as software/technical/camera tools. This is followed by $11.9 \%$ using the challenging questionnaires.

Finally, Table 10 shows a classification of the number of papers that have been cited by using "Scopus" as well as "Google Scholar" database in relation to Hajj and Umrah Services. The researches covered essential branches classified into the two holy mosques and the holy sites, the prearrival studies, housing and services studies, and transportation studies. The total overall researches are found to be 98, where their total Scopus and Google Scholar citations are estimated to be 228 and 315 , respectively.

Table 8 Research classifications according to statistical data type

\begin{tabular}{|c|c|c|c|c|c|c|}
\hline Statistical data type & $\begin{array}{l}\text { \# of } \\
\text { Researches } \\
(2016)\end{array}$ & $\begin{array}{l}\# \text { of } \\
\text { Researches } \\
(2017)\end{array}$ & $\begin{array}{l}\# \text { of } \\
\text { Researches } \\
(2018)\end{array}$ & $\begin{array}{l}\# \text { of } \\
\text { Researches } \\
(2019)\end{array}$ & $\begin{array}{l}\# \text { of } \\
\text { Researches } \\
(2020)\end{array}$ & References \\
\hline $\begin{array}{l}\text { Quantitative data (discontinuous/ } \\
\text { continuous) }\end{array}$ & 11 & 17 & 14 & 22 & 6 & $\begin{array}{c}{[23,26,27,36-46,48,50-63,65-72,} \\
74,76,78,87-93,95,96,99,100, \\
102,105-107,110-112,114-116, \\
118-121,124,125,127,129,130]\end{array}$ \\
\hline Qualitative (ordinal/nominal) & 1 & 2 & 3 & 3 & - & {$[41,49,50,55,57,64,73,106,108]$} \\
\hline $\mathrm{N} / \mathrm{a}$ & 5 & 6 & 5 & 6 & 1 & $\begin{array}{l}{[35,47,77,79-83,85,86,94,97,98,} \\
101,103,104,109,113,117,122, \\
123,126,128]\end{array}$ \\
\hline $\begin{array}{l}\text { Total percentage of statistical data } \\
\text { type }\end{array}$ & $16.7 \%$ & $24.5 \%$ & $21.6 \%$ & $30.4 \%$ & $6.9 \%$ & \\
\hline
\end{tabular}


Table 9 Research classifications according to data collection tools

\begin{tabular}{|c|c|c|c|c|c|c|}
\hline Data collection tools & $\begin{array}{l}\text { \# of } \\
\text { Researches } \\
(2016)\end{array}$ & $\begin{array}{l}\text { \# of } \\
\text { Researches } \\
(2017)\end{array}$ & $\begin{array}{l}\text { \# of } \\
\text { Researches } \\
(2018)\end{array}$ & $\begin{array}{l}\text { \# of } \\
\text { Researches } \\
(2019)\end{array}$ & $\begin{array}{l}\text { \# of } \\
\text { Researches } \\
(2020)\end{array}$ & References \\
\hline Virtual data & 1 & 4 & 5 & 8 & 1 & $\begin{array}{l}{[36-38,40,42-44,46,52,54,63,76} \\
\quad 95,108,110,112,114-116]\end{array}$ \\
\hline $\begin{array}{l}\text { Software/technical equipment/cam- } \\
\text { eras }\end{array}$ & 4 & 3 & 2 & 9 & 1 & $\begin{array}{l}{[38,39,41,65,69,78,89-92,103} \\
106,118-120,124,127,129,130]\end{array}$ \\
\hline Questionnaire & 1 & 5 & 5 & 1 & - & $\begin{array}{l}{[23,49,55-57,59-61,64,78,100,} \\
102]\end{array}$ \\
\hline $\begin{array}{l}\text { Official and administrative reports } \\
\text { and observations }\end{array}$ & 5 & 5 & 3 & 8 & 4 & $\begin{array}{l}{[23,26,27,45,50,51,53,58,62,64} \\
\quad 66,68,70-72,74,87,88,93,96, \\
99,105,107,111,125]\end{array}$ \\
\hline Interviews & 1 & & 2 & 1 & - & {$[55,57,73,121]$} \\
\hline $\mathrm{N} / \mathrm{a}$ & 5 & 6 & 5 & 5 & 1 & $\begin{array}{l}{[35,47,77,79-83,85,86,94,97,98,} \\
101,104,109,113,117,122,123, \\
128,129]\end{array}$ \\
\hline $\begin{array}{l}\text { Total percentage of data collection } \\
\text { tools }\end{array}$ & $16.8 \%$ & $22.8 \%$ & $21.8 \%$ & $31.7 \%$ & $6.9 \%$ & \\
\hline
\end{tabular}

Fig. 7 Percentages of preferred research data tactics among researches

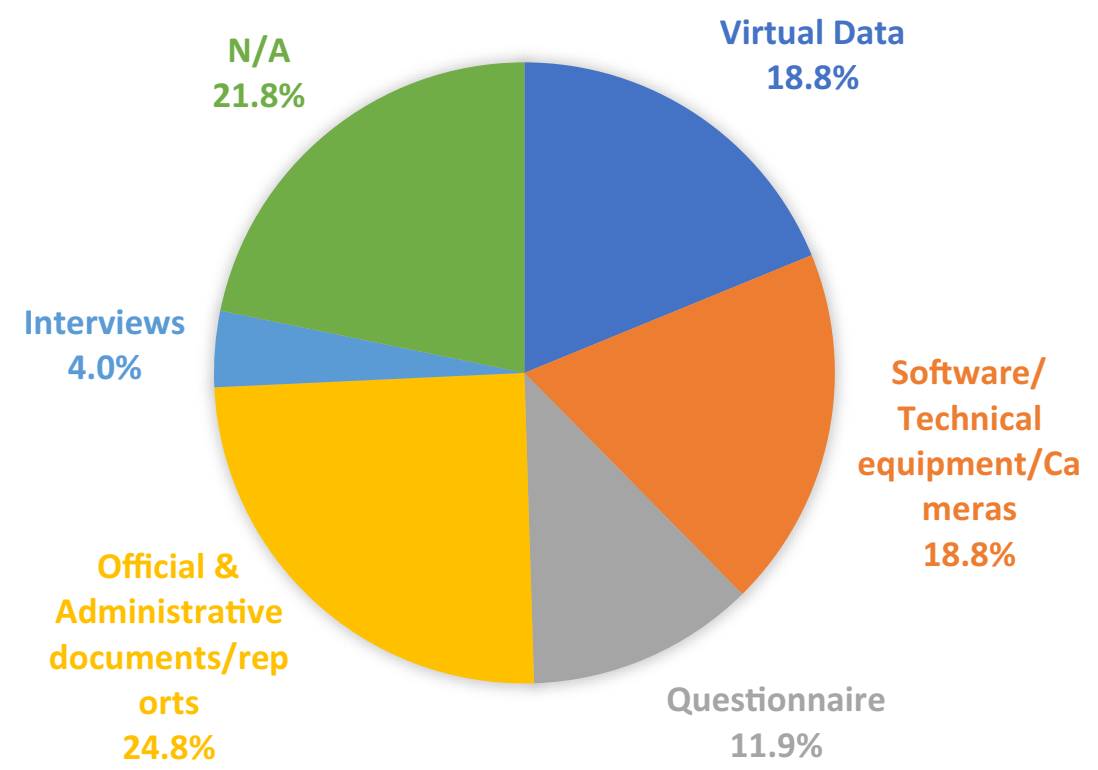

Table 10 Research citations according to Scopus and Google Scholar databases

\begin{tabular}{|c|c|c|c|}
\hline Research branches & \# Of research papers & \# Of citations (scopus) & \# Of citations (google scholar) \\
\hline The two holy mosques and the holy sites & 11 & 8 & 10 \\
\hline The pre-arrival studies & 15 & 18 & 41 \\
\hline Housing and services studies & 40 & 106 & 155 \\
\hline Transportation studies & 32 & 96 & 109 \\
\hline Overall related researches all together & 98 & 228 & 315 \\
\hline
\end{tabular}


These databases results indicate a relatively weak research studies and citation regarding the two holy mosques and holy sites, which is considered low, as can be visualized in percentages shown in Figs. 8 and 9.

\section{Research Proposals that can be Applied in the Hajj and Umrah System}

This section provides some research ideas and practical suggestions that employ technologies to facilitate the services provided to pilgrims, Umrah performers, visitors and service providers. The service providers considered are from all governmental, private and charitable sectors, which we hope will be useful to decision-makers within Hajj and Umrah systems, i.e., for applying their services, as briefed next.

\subsection{Smart Screen Devices}

The use of smart portable screen devices to eliminate the cases of losing pilgrims and Umrah performers. Screen devices are being distributed in certain places in the two holy cities, to help people know where they live in case they get lost. Where the missing person uses the bracelet on the device using (NFC) technology, and the device draws a path from his current location to the desired location using a map and estimates the distance and expected arrival time.

\subsection{Monitoring System for Abnormal Events}

There are many surveillance cameras used in the two holy mosques and the holy sites that perform various security tasks. To monitor all events through cameras, it requires follow-up, focus and great effort on the part of the observers. However, observers may not be able to notice an abnormal event early on, which in turn delays the action to avoid a problem.
Fig. 8 percentages of researches and their citations according to Scopus database
Fig. 9 percentages of researches and their citations according to Google Scholar database
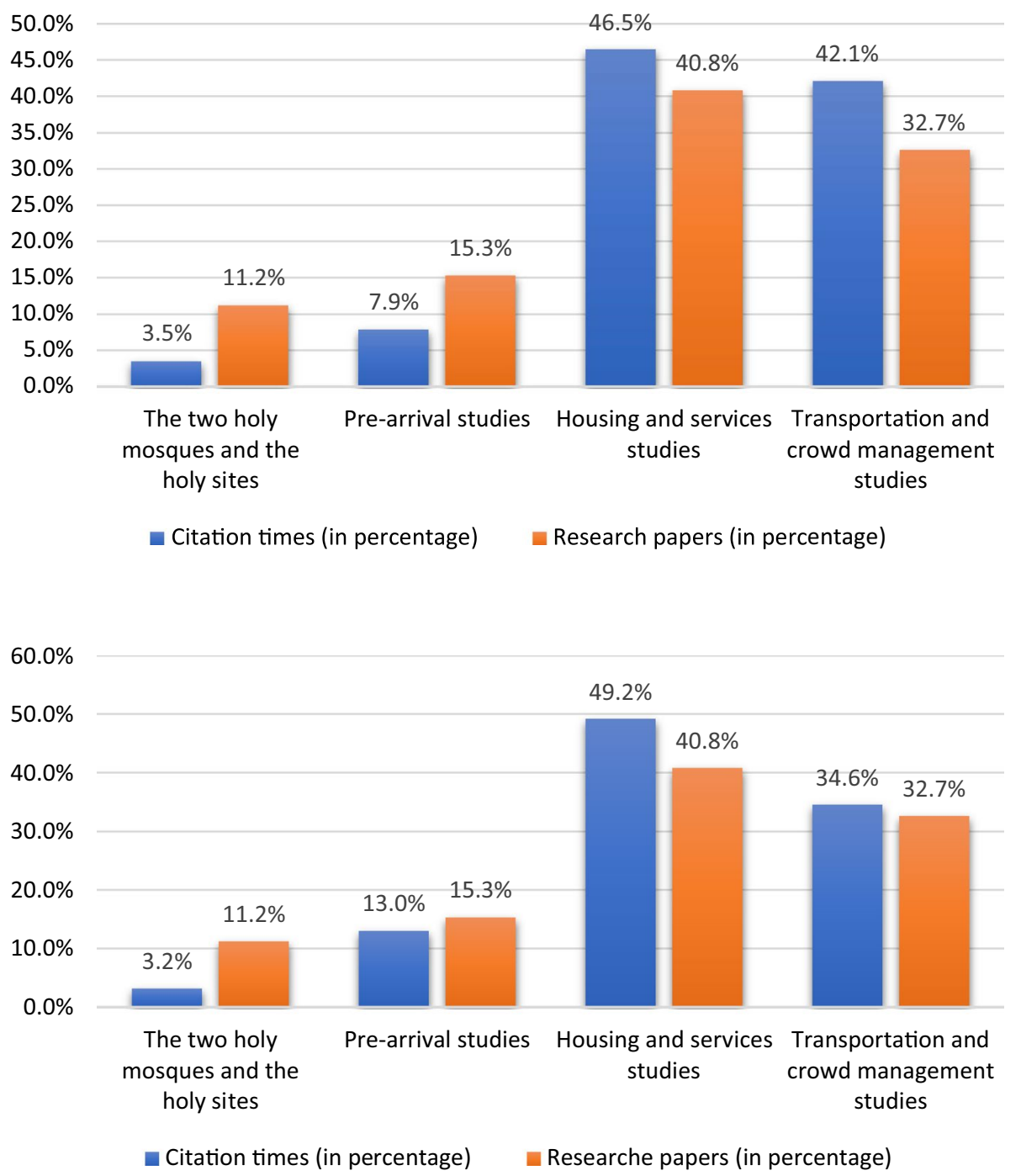


\subsection{Smart Parking System}

Developing interactive devices at the main exits leading to large car parks, such as the car parks in Madinah, which helps to identify the vehicle parking location through the vehicle plate number. The devices display the vehicle's image and guide the user to where the vehicle is parked through an interactive map on the screen, in addition to informing the driver of his/her current location.

\subsection{Cluster System}

Develop a tree-shaped cluster application to organize small groups of Hajj and Umrah performers, each group consists of 50-100 people supervised by a leader who has direct contact with them. The leader directs and identifies members of small groups, and easily locates each group member. The next level is between executives at a higher level, and so on, to facilitate communication and coordination between all pilgrims and Umrah performers, to find lost individuals, and to facilitate movement and mobility. In addition to disseminating information and instructions quickly and easily, even among individuals who do not have access to the Internet or smart devices, through direct communication with the group leader.

\subsection{Smart Buildings}

Expanding the use of the smart building concept using Internet of Things technology. This comes by automatically and smartly controlling the functions and state of the buildings through sensors that track the buildings' condition, as these sensors provide the necessary data required to automatically control the level of comfort and improve the use of available resources (such as energy and water), in addition to securing the place and maintaining the safety of its residents.

\subsection{Data and Artificial Intelligence Technologies}

Extracting different types of data such as tracking crowds, traffic congestion levels, street and road conditions, environmental conditions, and many others, as these data are processed with artificial intelligence techniques to reach solutions that support decision-makers.

\section{Open Challenges and Sophisticated-Related Issues}

The Hajj and Umrah system abounds with many open issues that need further professional scientific research. Accordingly, the most important open research issues are provided here, hoping to motivate the studies to be carried out relatively in the near future, as topics outlined next.

\subsection{Security and Privacy}

Very limited research has been observed in the area of technology security [131] and privacy [132] within the Hajj and Umrah E-Systems. This issue should be addressed in future studies of several topics, including social media [133], Language-related researches [134], smart cloud computing [135], IoT [136], healthcare information [137], medical assistances [138], data mining [139], and data communication [140].

\subsection{Big Data and IoT}

Big data and the IoT are promising research issues in the Hajj and Umrah system as they can be used to enhance data-based decision-making in many different areas [136], including business, social behavior, social services, healthcare, psychology, security, and much more [133]. Many researchers have proposed several frameworks to make use of big data as effectively as possible $[27,66,79,80]$. However, more research is still needed that addresses the benefits of big data and IoT considering the challenges of reliability and security [137].

\subsection{Virtual and Augmented Reality}

Some researchers have studied the use of virtual reality and augmented reality technology [55-61]. However, there is a need to study the possibility of expanding the use of this technology and study its impact on the beneficiaries of Hajj and Umrah performers.

\subsection{Sentiment Analysis}

Sentiment analysis is a process used to identify and categorize the opinions or feelings that come from users, whether they are found in texts (such as tweets, comments, or reviews) or images and videos (such as emojis or stickers) [19]. Recently, there are many studies that have addressed this issue using different techniques such as deep learningbased algorithms [141], and facial expression machine learning [142] as well as lexicon-based algorithms [143, 144]. Other studies have focused on capturing emotional and discriminative features from image and text content [145] and attention-based modality-gated networks for image-text sentiment analysis [146]. Likewise, this open issue lacks studies that attempt to analyze users' sentiments about issues related to the Hajj and Umrah system. Moreover, more research efforts should be made to study the performance [147], accuracy [148], and reliability [149] of sentiment 
analysis methods and their application to commonly used languages [150].

\subsection{Delay Minimization in Network Communication}

The people in the cities of Makkah and Madinah increases dramatically during the Hajj and Umrah seasons, as does their use of information technology and communication networks beside all IoT applications [122]. Hence, the quality of services provided over various communication networks is adversely affected [151]. There are some studies that have dealt with this issue in the literature such as the deployment framework discussion of fog computing during hajj [77] and smart crowd management via wireless and mobile technologies [123] as well as the framework remarks of secure mobile computing [78] and arithmetic hardware speeds analysis [152]. However, this delay minimization issue needs to be further considered in future research as it has not been sufficiently studied and explored from current integrated IoT smartness in terms of transmission cost [12], energy consumption [130], data transmission delay [152], security [3], reliability [4], scalability [153], computing efficiency [154].

\section{Conclusion}

This research presented an analytical study for the technologies and their applications in the Hajj and Umrah system during the last five years (2016-2020). The studied papers have been classified into four main branches, including studies of the two holy mosques and the holy sites, the prearrival studies, housing and services studies, and the transportation and crowd management studies. The results of the analysis showed that most of the reviewed researches were in 2018 , with a rate of $34.2 \%$. Also, the field of artificial intelligence was the most targeted area by researchers with $24.2 \%$. Moreover, the results showed that real implementation was the most used tool among researchers as ratioed at $42.3 \%$, followed by framework analysis at $20.2 \%$. Furthermore, the results revealed that the majority of researchers relied on the use of descriptive statistics in their data analysis and interpretation, at a rate of $73.5 \%$. Additionally, the most data collection method used by researchers is based on the use of official reports and observations with a rate of $24.8 \%$, as they are very clear and fixed, followed by virtual data and software/technical equipment/ cameras tools at $18.8 \%$ each. At end, the results illustrated a relatively weak research studies and citation regarding the two holy mosques and holy sites as compared to other research branches. Finally, this research was concluded with some research ideas and practical suggestions that can be applied in the two holy mosques and the holy sites to serve pilgrims,
Umrah performers, visitors and those who provide services to them. For future work examples, it is recommended to do research on helping Hajj and Umrah decision-makers by involving IoT smart devices using NFC as well as optimizing surveillance systems for abnormal activities. Also, many research studies can be performed to apply innovative smart parking schemes for vehicle arrangements and cluster hierarchy and smart buildings techniques for human grouping and interaction activities. It is believed that this research is just building the fundamental background for coming IoT technology research to come improving Hajj and Umrah world class services.

Acknowledgements Thanks to Umm Al-Qura University for motivating this collaborative research.

Funding There is no funding source.

\section{Declarations}

Ethical Approval This article does not contain any studies with human participants or animals performed by any of the authors.

Informed Consent Informed consent was obtained from all individual participants included in the study.

\section{References}

1. Alsaidi, A.; Gutub, A.; Alkhodaidi, T.: Cybercrime on transportation airline. J. Forensic Res. 10(4), 449 (2019)

2. Al-Shaarani, F.; Basakran, N.; Gutub, A.: Sensing e-banking cybercrimes vulnerabilities via smart information sciences strategies. RAS Eng. Technol. 1(1), 1-9 (2020)

3. Bin-Hureib, E.; Gutub, A.: Enhancing medical data security via combining elliptic curve cryptography and image steganography. Int. J. Comput. Sci. Netw. Secur. (IJCSNS) 20(8), 1-8 (2020). https://doi.org/10.22937/IJCSNS.2020.20.08.1

4. Samkari, H.; Gutub, A.: Protecting medical records against cybercrimes within Hajj period by 3-layer security. Recent Trends Inf. Technol Appl. 2(3), 1-21 (2019). https://doi.org/10. 5281/zenodo. 3543455

5. Alassaf, N.; Gutub, A.: Simulating light-weight-cryptography implementation for IoT healthcare data security applications. Int. J E-Health Med. Commun. (IJEHMC) 10(4), 1-15 (2019). https://doi.org/10.4018/IJEHMC.2019100101

6. Almutairi, S.; Gutub, A.; Al-Ghamdi, M.: Image steganography to facilitate online students account system. Rev. Bus. Technol Res. (RBTR) 16(2), 43-49 (2019). https://doi.org/10.13140/ RG.2.2.32048.30727

7. Aly, S.; AlGhamdi, T.; Salim, M.; Amin, H.; Gutub, A.: Information gathering schemes for collaborative sensor devices. Procedia Comput. Sci. 32, 1141-1146 (2014). https://doi.org/10.1016/j. procs.2014.05.545

8. Aljammal, A.H.; Bani-Salameh, H.; Qawasmeh, A.; Alsarhan, A.; Otoom, A.F.: A new technique for data encryption based on third party encryption server to maintain the privacy preserving in the cloud environment. Int. J. Bus. Inf. Syst. 28(4), 393-403 (2018) 
9. Dhou, K.: A novel investigation of attack strategies via the involvement of virtual humans: a user study of Josh Waitzkin, a virtual chess grandmaster. In: International Conference on Human-Computer Interaction (pp. 658-668). Springer, Cham (2020)

10. Fonseca, B.J.B.: Optimizing thresholds of the scan statistic to improve its worst case detection performance in sensor detection systems. IEEE Trans. Signal Inf. Process. Over Netw. 7, 249-258 (2021)

11. Ciuonzo, D.; Rossi, P.S.; Varshney, P.K.: Distributed detection in wireless sensor networks under multiplicative fading via generalized score-tests. IEEE Internet of Things J. 8(11), 9059-9071 (2021)

12. Altaf, A.; Abbas, H.; Iqbal, F.; Khan, M.M.Z.M.; Rauf, A.; Kanwal, T.: Mitigating service-oriented attacks using context-based trust for smart cities in IoT networks. J. Syst. Architect. 115, $1-12(2021)$

13. Sengupta, S.; Bhunia, S.S.: Secure data management in cloudlet assisted IoT enabled e-health framework in smart city. IEEE Sens. J. 20(16), 9581-9588 (2020). https://doi.org/10.1109/ JSEN.2020.2988723

14. Gotarane, V.; Raskar, S.: IoT practices in military applications. In: IEEE 3rd International Conference on Trends in Electronics and Informatics (ICOEI), pp. 891-894 (2019)

15. Kim, S.; Guy, S.; Hillesland, K.; Zafar, B.; Gutub, A.; Manocha, D.: Velocity-based modeling of physical interactions in dense crowds. Vis. Comput. 31, 541-555 (2015)

16. Almutairi, S.; Gutub, A.; Al-Juaid, N.: Motivating teachers to use information technology in educational process within Saudi Arabia. Int. J. Technol. Enhanced Learn. (IJTEL) 12(2), 200-217 (2020). https://doi.org/10.1504/IJTEL.2020.10027118

17. AlAssaf, N.; AlKazemi, B.; Gutub, A.: Applicable light-weight cryptography to secure medical data in IoT systems. J. Res. Eng. Appl. Sci. (JREAS) 2(2), 50-58 (2017). https://doi.org/10.46565/ jreas.2017.v02i02.002

18. Aly, S.; Alghamdi, T.; Salim, M.; Gutub, A.: Data dissemination and collection algorithms for collaborative sensor devices using dynamic cluster heads. Trends Appl. Sci. Res. 8(2), 55-72 (2013). https://doi.org/10.3923/tasr.2013.55.72

19. Bataineh, B.M.A.; Shambour, M.K.: A robust algorithm for emoji detection in smartphone screenshot images. J. ICT Res Appl. 13(3), 192-212 (2019)

20. Shambour, M.K.Y.: Vibrant search mechanism for numerical optimization functions. J. Inf. Commun. Technol. 17(4), 679-702 (2018)

21. Aljammal, A.H.; Manasrah, A.M.; Abdallah, A.E.; Tahat, N.M.: A new architecture of cloud computing to enhance the load balancing. Int. J. Bus. Inf. Syst. 25(3), 393-405 (2017)

22. Shambour, M.K.Y.: Adaptive multi-crossover evolutionary algorithm for real-world optimisation problems. Int. J. Reason.-based Intell. Syst. 11(1), 1-10 (2019)

23. Khan, E.; Shambour, M.: An analytical study of mobile applications for Hajj and Umrah services. Appl. Comput. Inf. 14(1), 37-47 (2017)

24. Curtis, S.; Zafar, B.; Gutub, A.; Manocha, D.: Right of way: asymmetric agent interactions in crowds. Vis. Comput. 29(12), 1277-1292 (2013). https://doi.org/10.1007/s00371-012-0769-x

25. Kaysi, I.; Alshalalfah, B.; Shalaby, A.; Sayegh, A.; Sayour, M.; Gutub, A.: Users' evaluation of rail systems in mass events: case study in Mecca, Saudi Arabia. Transp. Res. Rec. 2350(1), 111-118 (2013). https://doi.org/10.3141/2350-13

26. Gutub, A.; Aly, S.: Trialing a smart face-recognition computer system to recognize lost people visiting the two holy mosques. Arab J. Forens. Sci. Forens. Med. (AJFSFM) 1(8), 1120-1132 (2019). https://doi.org/10.26735/16586794.2018.037
27. Gutub, A.; Alharthi, N.: Improving Hajj and Umrah services utilizing exploratory data visualization techniques. In: 16th Scientific Symposium for Hajj, Umrah \& Madinah Visit, pp. 561-572 (2016)

28. Afzal, M.; Fatima, K.; Khalid, P.; Abbas, A.; Durrani, S.; Sajid, A.; Zaheer, M.: Internet of things its environmental applications and challenges. Environ. Contam. Rev. (ECR) 1(2), 1-3 (2018)

29. Kubler, S.; Robert, J.; Hefnawy, A.; Främling, K.; Cherifi, C.; Bouras, A.: Open IoT ecosystem for sporting event management. IEEE Access 5, 7064-7079 (2017)

30. Abdelgawad, H.; Shalaby, A.; Abdulhai, B.; Gutub, A.: Microscopic modeling of large-scale pedestrian-vehicle conflicts in the city of Madinah, Saudi Arabia. J. Adv. Transp. 48(6), 507-525 (2014). https://doi.org/10.1002/atr.1201

31. Kaysi, I.; Alshalalfeh, B.; Sayour, M.; Gutub, A.: Rapid transit service in the unique context of Holy Makkah: Assessing the first year of operation during the 2010 pilgrimage season. WIT Trans. Built Environ. 128, 253-267 (2012). https://doi.org/10. 2495/UT120231

32. Farooqi, N.; Gutub, A.; Khozium, M.O.: Smart community challenges: Enabling IoT/M2M technology case study. Life Sci. J. 16(7), 11-17 (2019). https://doi.org/10.7537/marslsj160719.03

33. Kumar, D.P.; Amgoth, T.; Annavarapu, C.S.R.: Machine learning algorithms for wireless sensor networks: a survey. Inf. Fus. 49, 1-25 (2019)

34. Hajj and Umrah vision realization program. (2019). vision2030. gov.sa, p. 10, last accessed May.2021

35. Shambour, M.; Khan, E.; Salibi, A.: Distribute Mina camps automatically to increase the capacity and efficiency. In: 17 th Scientific Symposium for Hajj, Umrah \& Madinah Visit, pp. 720-726 (2017).

36. Shambour, M.; Khan, E.: Heuristic approach for distributing pilgrims over mina tents. J. King Abdulaziz Univ. Eng. Sci. 30(2), 11-23 (2019)

37. Al-Quhtani, A.: Multi-purpose wireless sensor network using massive MIMO technology over Hajj area. In: 17th Scientific Forum for the Research of Hajj, Umrah and Madinah Visit, pp. 173-180 (2017)

38. Haase, K.; Kasper, M.; Koch, M.; Müller, S.: A pilgrim scheduling approach to increase safety during the Hajj. Oper. Res. 67(2), 376-406 (2019)

39. Yasein, M.; Khan, E.; Shambour, M.: Towards smart camps in Mina Holy place: exploiting IoT technologies. In: 19th Scientific Forum for the Research of Hajj, Umrah and Madinah Visit, pp. 123-132 (2019)

40. Yasein, M.: Regulating access to El-Salam Gate in the Prophet's Mosque at peak times during holidays using simulation. In: 16th Scientific Symposium for Hajj, Umrah \& Madinah Visit, 10 (2016)

41. Felemban, E.; Qahtani, K.; Hawsawi, A.; \& Shahri, A. Crowd simulation model for crowd movement in the holy mosque. In: 17th Scientific Symposium for Hajj, Umrah \& Madinah Visit, pp. 727-737 (2017)

42. Ali, G.; Al-Masud, S.: Routing optimization in WBAN using bees algorithm for overcrowded Hajj environment. Int. J. Adv. Comput. Sci. Appl. 9(5), 75-79 (2018)

43. Yasein, M.; Al-Gamal, M.; Shambour, M. Crowd movement analysis in Al-Masjed Al-Nabawi using modeling and simulation. In: 18th Scientific Forum for the Research of Hajj, Umrah and Madinah Visit, pp. 4-13 (2018)

44. AlQurashi, R.; Altman, T.: Multi-level multi-stage agent-based simulation model of crowd dynamics in last floor of Al- Haram Al-Sharif. In: 19th Scientific Forum for the Research of Hajj, Umrah and Madinah Visit, pp. 159-167 (2019) 
45. Rehman, F.; Felemban, E.: A preference-based interactive tool for safe rescheduling of groups for Hajj. In: IEEE/ACS 16th International Conference on Computer Systems and Applications (AICCSA), pp. 1-2 (2019)

46. Majid, A.; Hamid, N.; Rahiman, A.; Zafar, B.: GPU-based optimization of pilgrim simulation for Hajj and Umrah rituals. Pertanika J. Sci. Technol. 26(3), 1019-1038 (2018)

47. Mohamed, S.A.E.; Parvez, M.T.: Crowd modeling based auto activated barriers for management of pilgrims in Mataf. In: IEEE International Conference on Innovative Trends in Computer Engineering (ITCE), pp. 260-265 (2019)

48. Hamroun, M.; Lajmi, S.: An efficient multi-language video search engine to facilitate the Hajj and Umrah. In: 17th Scientific Forum for the Research of Hajj, Umrah and Madinah Visit, pp. 1-8 (2017)

49. Shambour, M.; Yasein, M.; Al-Gammal, M.; Bataineh, B.: Technical evaluation of web sites that include Hajj and Umrah services: an analytical study. In: 18th Scientific Symposium for Hajj, Umrah \& Madinah Visit, pp. 154-162 (2018)

50. Elgamal M.; Alshamarani, M.: an analytical study of the most important characteristics of the guests of Al-Rahman and their representation using modern technologies to mining large data to support the decision-making process. In: 19th Scientific Forum for the Research of Hajj, Umrah and Madinah Visit, pp. 285-294 (2019)

51. Khoj.; Issa. Decision support system for health centers in disaster management in the holy capital. In: 16th Scientific Forum for the Research of Hajj, Umrah and Madinah Visit, pp. 285-294 (2016)

52. Utama, D.; Faturrahman, M.; Rusdi, M.; Saputra, I.; Isnaeni, F.; Waspodo, B.: FHC-optimization model for deciding the objective Hajj pilgrims to restricted quota (Case Study: Hajj Pilgrimage Procedure in Indonesia). In: IEEE International Conference of Artificial Intelligence and Information Technology (ICAIIT), pp. 302-309 (2019)

53. Basalamah, S.; Rehman, F.: A survey on Hajj mobile applications. IJCSNS Int. J. Comput. Sci. Netw. Secur. 20(1), 208583208609 (2020)

54. Khwaja, A.: A real-time DBMS system for the immigration processing of large Hajj crowd. Int. J. Mod. Educ. Comput. Sci. (IJMECS) 9(9), 32-41 (2017)

55. Setyawan, A.; Wantini, W.: Developing a 3D-media simulation to improve Hajj spiritual intelegence in the grade XI SMK Muhammadiyah. Profunedu International Conference Proceeding 1, 71-78 (2018)

56. Isa, W.; Rozaimee, A.; Satar, S.; Hamid, N.; Rahim, N.; Hashim, J.; Abdullah, W.: Evaluation of user interface satisfaction for virtual Umrah among secondary school students. Adv. Sci. Lett. 23(5), 4149-4152 (2017)

57. Jamil, I.; Kadir, Z.: Interactive multimedia for learning Hajj. J. Contemp. Islamic Stud. 2(1), 85-86 (2016)

58. Bhatti, Z.; Waqas, A.; Malik, H.: Multimedia based learning and virtual tour for performing Hajj. J. Inf. Commun. Technol. (JICT) 12(1.6), 37-42 (2018)

59. Nassr, R.; Almalki, H.; Musa, S.; Aborujilah, A.: Pilgrims' acceptance of using augmented reality applications while performing the Hajj. Int. J. Eng. Technol. 7(4.29), 69-71 (2018)

60. Alsaif, A.: Teaching the Hajj using virtual simulation technology with middle school students in Saudi Arabia. Sci. J. Faculty Educ.-Assiut Univ. 452(5423), 1-34 (2017)

61. Utami, A.; Nadziroh, F.: The Infographic Umrah Guidebook "Umrah Grafis" based on augmented reality technology. In: International Conference on Science and Technology for an Internet of Things. European Alliance for Innovation (EAI). pp. 1-10 (2018). https://doi.org/10.4108/eai.19-10-2018.2282529
62. Shambour, M.; Bataineh, B.; Shamarani, M.; Yasein, M.: Forecasting the quantities of electricity and water needs required for the Makkah Region during the next Ramadan seasons. In: 17th Scientific Symposium for Hajj, Umrah \& Madinah Visit, pp. 304-311 (2017)

63. Morgan, A.; Khayyat, K.: Optimal distribution of service point in holy places. In: 18th Scientific Forum for the Research of Hajj, Umrah and Madinah Visit, pp. 14-24 (2018)

64. Khairullah \& Ashari: User preferences- based recommendation algorithm case study: Hajj and Umrah Agencies. In: 19th Scientific Forum of Hajj, Umrah and Madinah Visit Research, 10 (2019)

65. Munir, S. et al.: Modelling PM10 emissions from fossil fuels combustion using ADMS-urban in the holy city of Makkah-a focus on Hajj and Umrah seasons. In: 16th Scientific Forum for the Research of Hajj, Umrah and Madinah Visit, pp. 161-171 (2016)

66. Alharthi, N.; Gutub, A.: Data visualization to explore improving decision-making within Hajj Services. Sci. Model. Res. 2(1), 9-18 (2017). https://doi.org/10.20448/808.2.1.9.18

67. Alkhateeb, J.: A new framework for identifying the missed pilgrims in Hajj and Umrah. Oriental J. Comput. Sci. Technol. 10, 718-724 (2017)

68. Hijry, H.; Olawoyin, R.: Application of machine learning algorithms for patient length of stay prediction in emergency department during Hajj. In: IEEE International Conference on Prognostics and Health Management (ICPHM), pp. 1-8 (2020)

69. Baqui, M.; Löhner, R.: Towards real-time monitoring of the Hajj. In: Proceedings from the 9th International Conference on Pedestrian and Evacuation Dynamics (PED2018), pp. 394-402 (2018)

70. Alshammari, S.; Gwalani, H.; Helsing, J.; Mikler, A.: Disease spread simulation to assess the risk of epidemics during the global mass gathering of Hajj pilgrimage. In: IEEE Winter Simulation Conference (WSC), pp. 215-226 (2019)

71. Snoussi, S.; Wahabi, Y.: Arabic document segmentation on a smartphone towards Big Data HAJJ rules extraction. In: IEEE International Workshop on Arabic Script Analysis and Recognition (ASAR), pp. 109-113 (2017)

72. Batarfi, O.; Dahab, M.; Ezz, A.: Building an Arabic semantic lexicon for Hajj. Int. J. Comput. Appl. 181(I39), 9-15 (2019)

73. Qurashi, J.; Sharpley, R.: The impact of smart media technologies on the spiritual experience of Hajj pilgrims. Int. J. Religious Tourism Pilgrimage 6(3), 37-48 (2018)

74. Elgamal, M.: Sentiment analysis methodology of twitter data with an application on Hajj season. Int. J. Eng. Res. Sci. (IJOER) 2(1), 82-87 (2016)

75. Altalhi, S.; Gutub, A.: A survey on predictions of cyberattacks utilizing real-time twitter tracing recognition. J. Ambient Intell. Human. Comput. (2021). https://doi.org/10.1007/ s12652-020-02789-z

76. Jassas, M.; Abdallah, Shambour, M.: An intelligent system connecting medical sensors and the cloud to decrease the required time of serving a large number of patients during Hajj. In: 19th Scientific Forum for the Research of Hajj, Umrah and Madinah Visit, pp. 295-301 (2019)

77. Alraddady, S.; Li, A.; Soh, B.; Alzain, M.: Deployment of fog computing during Hajj season: a proposed framework. Procedia Comput. Sci. 161, 1072-1079 (2019)

78. Rahman, A.; Hassanain, E.; Hossain, M.: Towards a secure mobile edge computing framework for Hajj. IEEE Access $\mathbf{5}$, 11768-11781 (2017)

79. Nafea, I.: Mobile health application running on public cloud during Hajj. In: International Conference on Mobile Web and Information Systems, 10486, pp. 129-136. Springer (2017) 
80. Nafea, I.: Utilizing big data analysis for diseases prevention and control during Hajj. In: IEEE International Conference on Open and Big Data (OBD), pp. 52-56 (2016). https://doi.org/10.1109/ OBD.2016.15

81. Eldein, A.; Ammar, H.: Requirements model for Hajj and Umrah mobile healthcare system (HUMHS). Int. J. Islamic Appl. Comput. Sci. Technol. 5(1), 53-62 (2017)

82. Malik, H.; Abid, F.; Gilal, A.; Raja, A.: Use of cloud computing in Hajj crowed management and complex systems. In: IEEE International Conference on Engineering Technologies and Applied Sciences (ICETAS), pp. 1-5 (2017)

83. Al Masud, S.M.R.; Bakar, A.A.; Yussof, S.; Ali, G.A.; Mostafa, V.: A conceptual framework of WMN enabled WBAN system for pilgrims' health monitoring during hajj in the kingdom Saudi Arabia. ARPN J. Eng. Appl. Sci. 2482-2489 (2018)

84. Suryawanshi, S.; Pujari, K.; Pandita, S.: A review on real time pilgrim tracking and health monitoring system using GSM, GPS and biomedical sensors. Int. J. Adv. Res. Electr. Electron. Instrum. Eng. 5(1), 170-174 (2016)

85. Al Masud, S.M.R.A.; Bakar, A.A.; Yussof, S.: Towards developing a MAC protocol for outer-WBAN communication for pilgrims' health monitoring during hajj: a feasibility study. Int. J. Eng. Technol. 7(3), 1263-1271 (2018)

86. Al Masud, S.M.R.; Bakar, A.A.; Yussof, S.; Ali, G.A.; Mostafa, V.: A conceptual framework of WMN enabled WBAN system for pilgrims' health monitoring during hajj in the kingdom Saudi Arabia. Int. J. Eng. Technol. 4(7), 5178-5187 (2018)

87. Al Masud, S.M.R.; Bakar, A.A.; Yussof, S.: A systematic review of technological issues in monitoring pilgrims' health during hajj: current state, challenges and future directions. J. Theor. Appl. Inf. Technol. 96(7), 1935-1950 (2018)

88. Abdelazeez, M.; Shaout, A.: Pilgrim communication using mobile phones. J. Image Gr. 4(1), 59-62 (2016). https://doi. org/10.18178/joig.4.1

89. Shaout, A.; Khan, S.: ALHAJJ - Hajj App for iOS. IIUM Eng. J. 17(1), 1-27 (2016)

90. Hanifa A.; Zulkifli A.; Omar N.; Zamani A.; Masrom S.: Context-aware crowd monitoring with dynamic multi-user tracking data. Int. J. Eng. Technol. 7(4), 300-305 (2018)

91. Budiawan, M.; Afrianto, I.: Development of android based Hajj and Umrah pilgrims monitoring application in Dago Wisata International. Indonesian J. Comput. Cybern. Syst. (IJCCS) 14(3), 253-264 (2020)

92. Majid, H.; Azurah, A.; Lizawati, M.; Dewi, N.; Hisham, N.: HAJJRAH: an innovative application for pilgrims of Hajj and Umrah. ARPN J. Eng. Appl. Sci. 11(3), 1947-1950 (2016)

93. Aly, S.; Gutub, A.: Intelligent recognition system for identifying items and pilgrims. NED Univ. J. Res. 15(2), 17-23 (2018)

94. Rizwan, K.; Mahmood, N.; Nadeem, A.: Spatio-temporal database modeling and application for monitoring, tracking and assistance of Hujjaj during Hajj. In: International Conference on Engineering \& Emerging Technologies (ICEET), Superior University, Lahore, PK, pp. 7-8 (2016)

95. Nadeem, A.; Rizwan, K.; Syed, T.; Alkhodre, A.; Mehmood, A.: Spatio-temporal modeling and application for efficient online reporting and tracking of lost items during Huge Crowd Gatherings. Int. J. Comput. Digital Syst. 9(6), 1155-1163 (2020)

96. Shaout, A.; Oman, M.: Towards developing an intelligent HAJJ guide system. In: IEEE International Conference on Information Technology (ICIT), pp. 280-285 (2017)

97. Alsubhy, A.; Abi Sen, A.; Alahmadi, B.; Bahbouh, N.; AbiSen, H.: A model for tracking people and property in crowds. In: IEEE International Conference on Computing for Sustainable Global Development (INDIACom), pp. 244-248 (2020)
98. Yamin, M.; Al-Ahmadi, H.; Al Muhammad, A.: Integrating social media and mobile apps into Hajj management. In: IEEE International Conference on Computing for Sustainable Global Development (INDIACom), pp. 1368-1372 (2016)

99. Mohamed, H.; Arshad, M.; Azmi, M.: M-HAJJ DSS: a mobile decision support system for Hajj pilgrims. In: IEEE International Conference on Computer and Information Sciences (ICCOINS), pp. 132-136 (2016)

100. Elazhary, H.: Cloud-based context-aware mobile applications and framework for Hajj and Umrah management. Int. J. Comput. Trends Technol. 47(2), 106-115 (2017)

101. Yasein, M.; Alharthi, N.: A review of tracking technologies in Hajj and Umrah research. In: 17th Scientific Forum for the Research of Hajj, Umrah and Madinah Visit, pp. 1-11 (2017)

102. Osman, M.: A design of smart Hajj guides system for pilgrim identification and location services. Doctoral dissertation, Sudan University of Science \& Technology, pp. 1-108 (2018)

103. Alkhuzaim, B.; Altahhan, A.: Using convolution neural network for crowd density estimation for the holy Masjed. In: 19th Scientific Forum for the Research of Hajj, Umrah and Madinah Visit, pp. 133-141 (2019)

104. Jabbari, A.; Song, S.; Aal-Salem, M.: DEMO: dense mode mobile crowd sensing for collision prediction and protection. In: 17th Scientific Forum for the Research of Hajj, Umrah and Madinah Visit, pp. 1-9 (2017)

105. Musa, A.; Rahman, M.; Sadi, M.; Rahman, M.: Crowd reckoning towards preventing the repeat of '2015 Hajj pilgrims stampede'. In: IEEE International Conference on Electrical \& Electronic Engineering (ICEEE), pp. 1-4 (2017)

106. Khan, S.; Tayyab, M.; Amin, M.; Nour, A.; Basalamah, A.; Basalamah, S.; Khan, S.: Towards a crowd analytic framework for crowd management in Majid-al-Haram. pp. 1-11, arXiv preprint arXiv:1709.05952 (2017)

107. Felemban, E.; Fatani, A.; Rehman, F.: An optimized scheduling process for a large crowd to perform spatio-temporal movements safely during pilgrimage. In: IEEE International Conference on Big Data (Big Data), pp. 6049-6051 (2019)

108. Seddiq, Y.; Alharbiy, A.; GhunaimKing, M.: Crowd congestion assessment using multi-resolution clustering. In: 19th Scientific Forum for the Research of Hajj, Umrah and Madinah Visit, pp. 142-148 (2019)

109. Amer, M.; Almatrafi, A.: Using a multi-agent architecture to handle the negotiation between the Hajj authorities and the Hajj travel agents. In: 19th Scientific Forum for the Research of Hajj, Umrah and Madinah Visit, pp. 168-174 (2019)

110. Namoun, A.; Mir, A.; Alkhodre, A.; Tufail, A.; Alrehaili, A.; Farquad, M.; Benaida, M.: A multi-agent architecture for evacuating pilgrims in panic and emergency situations: the hajj scenario. J. Theor. Appl. Inf. Technol. 96(20), 6665-6676 (2018)

111. Felemban, E.; Rehman, F.; Naseer, A.; Biabani, S.: Inferring crowd trip informatics using mobile app in Hajj. IJCSNS Int. J. Comput. Sci. Netw. Secur. 20(9), 76-83 (2020)

112. Islam, S.; Kafi, A.; Islam, M.; Islam, N.; Ullah, M.: IoT based crowd congestion and stampede avoidance in Hajj using Wemos D1 with machine learning approach. In: IEEE International Conference on Electrical Information and Communication Technology (EICT), pp. 1-5 (2019)

113. Mohamed, M.; Shabayek, A.; El-Gayyar, M.: IoT-based framework for crowd management. mobile solutions and their usefulness in everyday life, pp. 47-61. Springer (2019)

114. Nasser, N.; Anan, M.; Awad, M.; Bin-Abbas, H.; Karim, L.: An expert crowd monitoring and management framework for Hajj. In: IEEE International Conference on Wireless Networks and Mobile Communications (WINCOM), pp. 1-8 (2017) 
115. Mahmood, I.; Haris, M.; Sarjoughian, H.: Analyzing emergency evacuation strategies for mass gatherings using crowd simulation and analysis framework: Hajj scenario. In: ACM SIGSIM Conference on Principles of Advanced Discrete Simulation, pp. 231-240 (2017)

116. Nasser, N.; El-Ouadrhiri, A.; El Kamili, M.; Ali, A.; Anan, M.: Crowd management services in Hajj: a mean-field game theory approach. In: IEEE Wireless Communications and Networking Conference (WCNC), pp. 1-7 (2019)

117. Mnasri, C.; Farhat, A.: Numerical simulation of the flow of crowds at the Jamarat Bridge during the Annual Hajj Event. Open J. Fluid Dyn. 6(04), 321 (2016)

118. Alazbah, A.; Zafar, B.: Pilgrimage (Hajj) crowd management using agent-based method. Int. J Found. Comput. Sci Technol. (IJFCST) 9(1), 1-117 (2019)

119. Felemban, E.; Rehman, F.U.; Biabani, A.A.; Naseer, A.; AlAbdulwahab, U.: Towards building an interactive platform for analyzing movement of buses in Hajj. In: IEEE International Conference on Big Data (Big Data), pp. 3775-3778 (2019)

120. Felemban, E.; Rehman, F.U.; Wadood, H.; Naseer, A.: Towards building evacuation planning platform using multimodal transportation for a large crowd. In: IEEE International Conference on Big Data (Big Data), pp. 4063-4066 (2019)

121. Alrabghi, A.: Modelling passengers flow at Hajj Terminal in Jeddah. Int. J. Simul. Syst. Sci. Technol. 1-7 (2019)

122. Yamin, M.: Managing crowds with technology: cases of Hajj and Kumbh Mela. Int. J. Inf. Technol. 11(2), 229-237 (2019)

123. Yamin, M.; Basahel, A.; Abi-Sen, A.: Managing crowds with wireless and mobile technologies. Wirel. Commun. Mob. Comput. 1-16 (2018)

124. Jabbari, A.; Almalki, K.J.; Choi, B.Y.; Song, S.: ICE-MoCha: intelligent crowd engineering using mobility characterization and analytics. Sensors, 19(5), 1025, 1-19 (2019)

125. Felemban, E.; Rehman, F.; Biabani, S.; Ahmad, A.; Naseer, A.; Majid, A.R.; Zanjir, F.: Digital revolution for Hajj crowd management: a technology survey. IEEE Access 8, 208583-208609 (2020)

126. Tufail, A.: Pilgrim tracking and location based services using RFID and wireless sensor networks. IJCSNS Int. J Comput. Sci Netw. Secur. 18(6), 112-119 (2018)

127. Al-Otaibi, A.; Fallata, Al-Otaibi, B.: Management of crowded places in Hajj using radio frequency identification, (Bachelor dissertation, Umm Al-Qura University), pp. 1-74 (2016)

128. Javed, Y.: Sensors-based crisis response and management for mass gatherings: a case of Hajj. In: Proceedings of the ISCRAM 2016 Conference, Rio de Janeiro, pp. 1-7 (2016)

129. Al Masud, S.M.R.; Bakar, A.A.; Yussof, S.: A modified WBANs MAC superframe using priority-criticality index table for managing pilgrims' emergency traffic in Hajj. Indonesian J Electr. Eng. Comput. Sci. 14(3), 1499-1507 (2019)

130. Al Masud, S.M.R.A.; Bakar, A.A.; Yussof, S.: A priority-queue dominated and delay-energy guaranteed MAC superframe structure for WBANs to deal with various emergency traffic of pilgrims during Hajj: an analytical model. (97)7, 1879-1890 (2019)

131. Gutub, A.; Al-Qurashi, A.: Secure shares generation via M-blocks partitioning for counting-based secret sharing. J. Eng. Res. 8(3), 91-117 (2020). https://doi.org/10.36909/jer.v8i3.8079

132. Alanazi, N.; Khan, E.; Gutub, A.: Involving spaces of unicode standard within irreversible Arabic text steganography for practical implementations. Arab. J. Sci. Eng. (AJSE) (2021). https:// doi.org/10.1007/s13369-021-05605-8

133. Gutub, A.: Social media \& its impact on e-governance. ME Smart Cities 2015. 4th Middle East Smart Cities Summit, Pullman Dubai Deira City Centre Hotel, Dubai, UAE (2015)

134. Gutub, A.; Fattani, M.: A novel Arabic text steganography method using letter points and extensions. Int. J. Comput. Electr.
Autom. Control Inf. Eng. 1(3), 502-505 (2007). https://doi.org/ 10.5281/zenodo. 1061621

135. Gutub, A.: Exploratory data visualization for smart systems. In: Smart Cities 2015 3rd Annual Digital Grids and Smart Cities Workshop, Burj Rafal Hotel Kempinski, Riyadh, Saudi Arabia (2015)

136. Gutub, A.; Alkhodaidi, T.: Smart expansion of target key for more handlers to access multimedia counting-based secret sharing. Multimedia Tools Appl. (MTAP) (2020). https://doi.org/10. 1007/s11042-020-08695-y

137. Alassaf, N.; Gutub, A.; Parah, S.; AlGhamdi, M.: Enhancing speed of SIMON: a light-weight-cryptographic algorithm for IoT applications. Multimedia Tools Appl. (MTAP) 78, 32633-32657 (2019). https://doi.org/10.1007/s11042-018-6801-z

138. Bin-Hureib, E.; Gutub, A.: Enhancing medical data security via combining elliptic curve cryptography with 1-LSB and 2-LSB image steganography. Int. J. Comput. Sci. Netw. Secur. (IJCSNS) 20(12), 232-241 (2020). https://doi.org/10.22937/IJCSNS.2020. 20.12.26

139. Hassan, F.; Gutub, A.: Efficient reversible data hiding multimedia technique based on smart image interpolation. Multimedia Tools Appl. (MTAP) 79(39), 30087-30109 (2020). https://doi.org/10. 1007/s11042-020-09513-1

140. Al-Nofaie, S.; Gutub, A.: Utilizing pseudo-spaces to improve Arabic text steganography for multimedia data communications. Multimedia Tools Appl. (MTAP) 79, 19-67 (2020). https://doi. org/10.1007/s11042-019-08025-X

141. Ombabi, A.H.; Ouarda, W.; Alimi, A.M.: Deep learning CNNLSTM framework for Arabic sentiment analysis using textual information shared in social networks. Soc. Netw. Anal. Min. 10(1), 1-13 (2020)

142. Meeki, N.; Amine, A.; Boudia, M.A.; Hamou, R.M.: Deep learning for non verbal sentiment analysis: facial emotional expressions, p. 1-11. Department of Computer Science, Tahar Moulay University of Saida, GeCoDe Laboratory (2020)

143. Al-Ghaith, W.: Developing lexicon-based algorithms and sentiment lexicon for sentiment analysis of Saudi Dialect Tweets. Int. J. Adv. Comput. Sci. Appl. 10(11), 83-88 (2019)

144. Taj, S.; Shaikh, B.B.; Meghji, A.F.: Sentiment analysis of news articles: a lexicon based approach. In: IEEE International Conference on Computing, Mathematics and Engineering Technologies (iCoMET), pp. 1-5 (2019)

145. Xu, J.; Li, Z.; Huang, F.; Li, C.; Philip, S.Y.: Social image sentiment analysis by exploiting multimodal content and heterogeneous relations. IEEE Trans. Ind. Inf. 17(4), 2974-2982 (2020)

146. Huang, F.; Wei, K.; Weng, J.; Li, Z.: Attention-based modalitygated networks for image-text sentiment analysis. ACM Trans. Multimedia Comput. Commun. Appl. (TOMM) 16(3), 1-19 (2020)

147. Gutub, A.; Al-Ghamdi, M.: Hiding shares by multimedia image steganography for optimized counting-based secret sharing. Multimedia Tools Appl. (MTAP) 79, 7951-7985 (2020). https://doi. org/10.1007/s11042-019-08427-x

148. AlKhodaidi, T.; Gutub, A.: Trustworthy target key alteration helping counting-based secret sharing applicability. Arabian J. Sci. Eng. (AJSE) 45, 3403-3423 (2020). https://doi.org/10.1007/ s13369-020-04422-9

149. Al-Qurashi, A.; Gutub, A.: Reliable secret key generation for counting-based secret sharing. J. Comput. Sci. Comput. Math. (JCSCM) 8(4), 87-101 (2018). https://doi.org/10.20967/jcscm. 2018.04.006

150. Gutub, A.; Alaseri, K.: Hiding shares of counting-based secret sharing via arabic text steganography for personal usage. Arab. J. Sci. Eng. (AJSE) 45, 2433-2458 (2020). https://doi.org/10.1007/ s13369-019-04010-6 
151. Hassnawi, L.; Ahmad, R.B.; Yahya, A.; Aljunid, S.; Ali, Z.: Performance analysis of workload effects over motorway wireless ad hoc camera networks. Int. J. Adv. Comput. Technol. (IJACT) 5(10), 117-125 (2013)

152. Gutub, A.: High speed hardware architecture to compute GF(p) montgomery inversion with scalability features. IET Comput. Digital Tech. 1(4), 389-396 (2007). https://doi.org/10.1049/ietcdt:20060183
153. Gutub, A.; Tenca, A.: Efficient scalable VLSI architecture for montgomery inversion in GF(p). Integr. VLSI J. 37(2), 103-120 (2004). https://doi.org/10.1016/j.vlsi.2003.12.001

154. Savas, E.; Naseer, M.; Gutub, A.; Koc, C.K.: Efficient unified montgomery inversion with multi-bit shifting. IEE Proc. Comput. Digit. Techn. 152(4), 489-498 (2005). https://doi.org/10. 1049/ip-cdt:20059032 